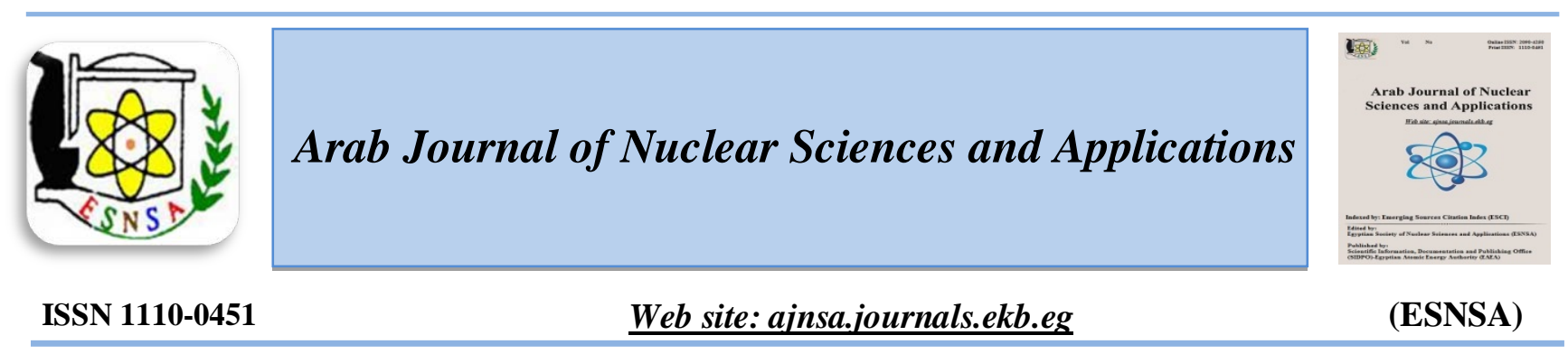

\title{
Effect of Small Additions of Indium on Transient and Steady-State Creep Characteristics, Microstructure and Properties of Sn-9Zn lead-Free Solders
}

\author{
M. Y. Salem \\ Physics Department, Faculty of Science at New Valley, Assuit University, 72511, El-Kharga, Egypt
}

Received $21^{\text {st }}$ Nov. 2017 Accepted $23^{\text {rd }}$ April

Complete enforcement of the new propagation of lead-free solders needed detailed knowledge and comprehension of their mechanical attitude. In the present study transient and steady-state creep tests, microstructure and characteristic of Sn-9Zn lead free solders and Sn-9Zn-2In ternary alloys were studied under different five applied stresses ranging from ranged from 3.62 to $11.22 \mathrm{MPa}$ and in the temperature range from $323 \mathrm{~K}$ to $403 \mathrm{~K}$. It is obvious that the addition of Indium to the Sn-9Zn binary system lead to a reducing of the melting point, therefore, the Sn-9Z-2In solder material shows maximum ductility (strain) and well-behaved mechanical realization than that of eutectic Sn-9Zn commercial solder. Microstructural analysis revealed that the ternary alloys are more fine and refining than binary due to existence of $\gamma-\mathrm{InSn}_{4}$. The activation energy of transient creeps have been found to be $20.16-26.32$ and $16.80-22.44 \mathrm{~kJ} \mathrm{~mol}^{-1}$ in the low and high temperature regions for Sn-9Zn binary and Sn-9Z-2In ternary alloys respectively. The steady state creep was studied in the same temperature range under same loads. The strain rate sensitivity parameter $(\mathrm{m})$ has been found to elevate by elevating the applied temperature and stresses. The activation energies of steady state creep of the alloy have been found to be 26.31-30.82 and $23.36-27.13 \mathrm{~kJ} \mathrm{~mol}^{-1}$ in the low and high temperature regions for Sn-9Zn binary and Sn-9Z-2In ternary alloys, respectively.

Keywords: Steady state creep / Transient creep / Activation energies

\section{Introduction}

Conventional Sn-Pb solders have been extensively utilized as the common materials for electronic packaging, since they have a low melting point, of low cost and good wettability [1]. Regardless of all of these characteristics, scientific efforts have been made to replace these toxic Pb-based solders, used in the packaging operation of electronic devices, by non-toxic solders. Numerous studies have been conducted to develop new Pb-free solders [2,3]. New solders should be of a minimum material cost, excellent wettability, accepted melting temperature, perfect mechanical and electrical properties, high corrosion resistance and acceptability for health and circumference [4].
Numerous types of binary and ternary Sn-based lead-free solders such as; Sn-Zn, Sn-Ag, Sn-Zn-In, have been progressively used in the electronic packaging industry [5-7].

Binary or ternary Sn-based lead-free alloys are actually accepted as substituents to Pb-solders [8]. Amongst these binary alloys, the Sn-Zn system is the most hopeful substituent due to its excellent ductility, creep resistance and thermal resistance $[9,10]$. Numerous researches have been conducted on adding a third element, such as In to the Sn-Zn solder [11] to achieve the required properties. The selected samples for solders are stringent and perform a significant role in solder joint reliability [12].

Corresponding author: mahmoud_salem569@yahoo.com

DOI: $\underline{10.21608 / a j n s a .2135 .1015}$

(C) Scientific Information, Documentation and Publishing Office (SIDPO)-EAEA 
Many types of Sn-based lead-free solders such as $\mathrm{Sn}-\mathrm{Ag}, \mathrm{Sn}-\mathrm{Cu}, \mathrm{Sn}-\mathrm{Ag}-\mathrm{Cu}$ and $\mathrm{Sn}-\mathrm{Zn}$ have been progressively used in the electronic packaging industry $[13,14]$. Amongst them the Sn-Zn solder has been suggested as one of the most promising substituents for lead-containing solder for wave, dip, and iron soldering processes [15].

Among the lead-free solders, eutectic or near eutectic Sn-Zn solder is regarded as a suitable replacement for $\mathrm{Sn}-\mathrm{Pb}$ solders because its melting temperature $(471 \mathrm{~K})$ is near to that of $\mathrm{Sn}-\mathrm{Pb}$ eutectic alloy $(456 \mathrm{~K})$, and can offer better mechanical properties with overall cost effectiveness [16,17]. Different other universal alloying element, $\mathrm{Zn}$ is effective both chemically and metallurgically. In spite of the fact that $\mathrm{Zn}$ in Sn-Zn samples can be easily oxidized to form corrosion products (e.g., Zn oxide/hydroxide and $\mathrm{ZnCl}_{2}$ ), which leads to poor wettability and reduces the reliability of solder joints, certain Sn$\mathrm{Zn}$ composition region can act as a sacrificial anode with a perfect anticorrosive feature for the ferrous base mineral. Even if this is true, some accelerated tests to determine whether the solder structure can help improving Sn-Zn lead-free solders in confirmed special enforcement are still needed $[18,19]$.

According to Sn-Zn binary phase diagrams depicted in Fig.(15) [20], the tendency of liquidus bar in the near-eutectic point (hypoeutectic region) is totally minimum, i.e., the decrees in $\mathrm{Zn}$ content near Sn-9Zn will not impulse much increase in the equilibrium liquidus temperature. Therefore, it is possible to reduce the adverse effect of $\mathrm{Zn}$ by lowering its concentration, while mostly keeping its benefit of generating the eutectic melting point. It indicates that the price excess and oxidation softness of $\mathrm{Zn}$ connected depending on lead-free soldering can be decreased. While there have been some reports of the influence of $\mathrm{Zn}$ concentration on Sn-Zn alloys, the study of creep manner has been limited. Wei et al. [16] have examined the non equilibrium melting and wetting manner of a spectrum of $\mathrm{Sn}-\mathrm{Zn}$ alloys (2.5-9Zn) and organize that while $\mathrm{Sn}-6.5 \mathrm{Zn}$ posses the same manner as the eutectic Sn-9Zn in melting, it has safely preferable wettability to $\mathrm{Cu}$ than Sn-9Zn. They also suggested that using Sn-6.5Zn as a lead- free solder would be further helpful than using Sn-9Zn [21].

The present paper aims to explore the effects of few quantity of In on the microstructure and creep properties of Sn-9Zn binary lead-free solder alloys. It is obvious that the additions of Indium alloy to the Sn-9Zn binary lead to a reducing of the melting point to $460.9 \mathrm{~K}$ [22 ], therefore, the Sn-9Z-2In solder material exhibits a higher ductility and wellbehaved mechanical performance than those of eutectic Sn-9Zn commercial solder. Hopefully, these small element additions can play a positive role in the improvement of the overall mechanical properties of the Sn-9Sn based alloys. The 2In additions have been reported to improve the microstructure of Sn-9Sn alloys as well as their strength and ductility.

\section{Experimental Procedures}

Sn-9Zn binary, Sn-9Zn-2In ternary solder alloys were prepared from Sn, Zn, and In (purity 99.99\%) as raw materials by vacuum melting. The samples were derived into wires. In this study, the wires were annealed at $140 \mathrm{0C}$ for $2 \mathrm{~h}$ and then slowly cooled to room temperature at a cooling rate $\mathrm{T}^{\prime}=2 \times 10^{-2}$ $\mathrm{K} / \mathrm{sec}$. After this heat processing, the samples were annealed at room temperature for 7 days before testing. This process allowed a little quantity of grain growth and grain stabilization to occur [23]. The microstructure of the samples was studied using X-ray diffraction and SEM. Creep deformation were performed on annealed wire samples of $0.8 \mathrm{~mm}$ diameter and $5 \mathrm{~cm}$ standard length.

The samples were tested at five temperature range at under different stresses ranging from ranged from 3.62 to $11.22 \mathrm{MPa}$, using a classical type creep machine. The accuracy of temperature measurement is of the order \pm 1 K. Strain measurements were done with an accuracy of $\pm 1 \times 10^{-2}$. The used chamber temperature could be spotted by utilized a thermocouple touching with specimen. Table (1) list the true chemical compositions of the tested samples used Energy-dispersive X-ray spectroscopy (EDX) used in this investigation. A solution of $2 \% \mathrm{HCl}$, $3 \%$ HNO3 and 95\%(vol.\%) ethyl alcohol was prepared and used to etch the samples. 
Phase identity of the used samples achieved out by X-ray diffractometry (XRD) at $40 \mathrm{KV}$ and $20 \mathrm{~mA}$ using $\mathrm{Cu} \mathrm{K \alpha}$ radiation with

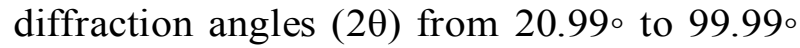
and a stationary scanning speed of $1 \% \mathrm{~min}$. The solder ingots were then mechanically machined into all wire samples.

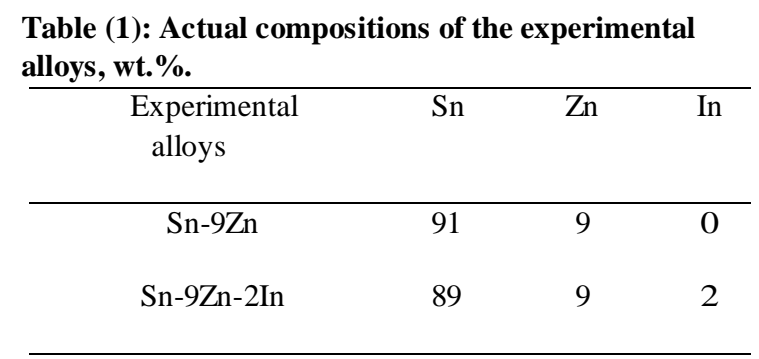

\section{Results and Discussion}

\section{Transient stage}

The transient creep interval is commonly described by Friadel's equation ${ }^{(24-26)}$ :

$$
\varepsilon_{\mathrm{tr}}=\beta \mathrm{t}^{\mathrm{n}}
$$

Where $\varepsilon_{\mathrm{tr}}$ and $\mathrm{t}$ are the transient creep strain, and time, $\beta$ and $\mathrm{n}$ are (transient creep parameters) constants relying on the experimental test conditions.

Isothermal creep curves for the two tested alloy were studied under five applied stresses ranged from 3.62 to $11.22 \mathrm{MPa}$ at five different working temperatures as seen Fig.1a-e. The gradation of creep curves with regard to the temperature display a acute rising in behavior particularly at high temperatures

Isothermal creep curves for the two tested alloy were studied at two different temperature 323K and $403 \mathrm{~K}$ and fixed applied stresses equal 11.22 MPa as seen in Fig.(2), it is seen that the ternary alloys is more superplastic than the binary at the two tested temperature.

In the present paper the relation between $\ln \varepsilon_{\text {tr }}$ and lnt gives straight lines as shown in Fig.(3a-e).

The exponent $\mathrm{n}$ was determined from the slope relate $\ln \varepsilon_{\text {tr }}$ and $\operatorname{lnt}$, while the parameter $\beta$ was calculated from the intercepts at $\operatorname{lnt}=0$ :

$$
\ln \beta=\left(\operatorname{lnt}_{2} \varepsilon_{\mathrm{tr} 1}-\operatorname{lnt}_{1} \varepsilon_{\mathrm{tr} 2}\right) / \operatorname{lnt}_{2}-\operatorname{lnt}_{1}
$$

It was found that $\mathrm{n}$ rises with rising deformation temperature and stresses see Fig.(4). The parameter $\beta$ was rising with rising temperature and rising the applied stress as seen Fig.(5).

Fig.(6,7) illustrates the relation between $\ln \varepsilon_{\mathrm{tr}}$ and $1000 / \mathrm{T}$ at low temperature for Sn-9Zn eutectic and Sn-9Zn-2In alloys for five different applied stresses.

The relation between coefficient $\beta$ and strain rate of the steady state creep $\left(\varepsilon_{\mathrm{St}}^{\cdot}\right)$ written in the equation ${ }^{(27)}$.

$$
\beta=\beta_{0}\left(\dot{\varepsilon}_{\text {st }}^{\cdot}\right)^{\gamma}
$$

Where, $\beta_{0}$ and $\gamma$ are constants depend on the experimental conditions.

\section{Steady-state creep stage}

For steady state the current examination shows that creep tests are extra sensitive to the divergence of the samples structure, this may reflect the influence of $\mathrm{Zn}$-atom on the behaviour of the samples see Fig.(1).

Steady state creep test were performed especially on Sn-9Zn lead free solders and Sn-9Zn-2In ternary alloys. The samples were examined in the temperature range from 323 to $403 \mathrm{~K}$ under stationary five applied stresses.

The steady-state strain rate $\varepsilon_{\text {st }}^{\circ}$ of the examined samples is calculated from the slopes of the linear parts of the acquired creep curves represented in Fig.(1a-e). It rises with rising both the $\mathrm{T}$ and $\sigma$ (stress) as shown in Fig.(8).

Strain rate sensitivity parameter $m=$ $\partial \ln \sigma / \partial \ln \varepsilon_{s t}$ was calculated from the inclination of the straight lines of $\ln \sigma$ and $\ln \varepsilon_{\text {st }}^{\circ}$ see Fig.(9). The activation energy of steady creep at stable load was studied utilize the following formula $[24,26]$.

$$
Q=R\left(\partial \ln \varepsilon_{s t} / \partial(1 / T)\right)
$$

where $T$ and $R$ are temperature (Kelvin), and the gas constant, respectively. 

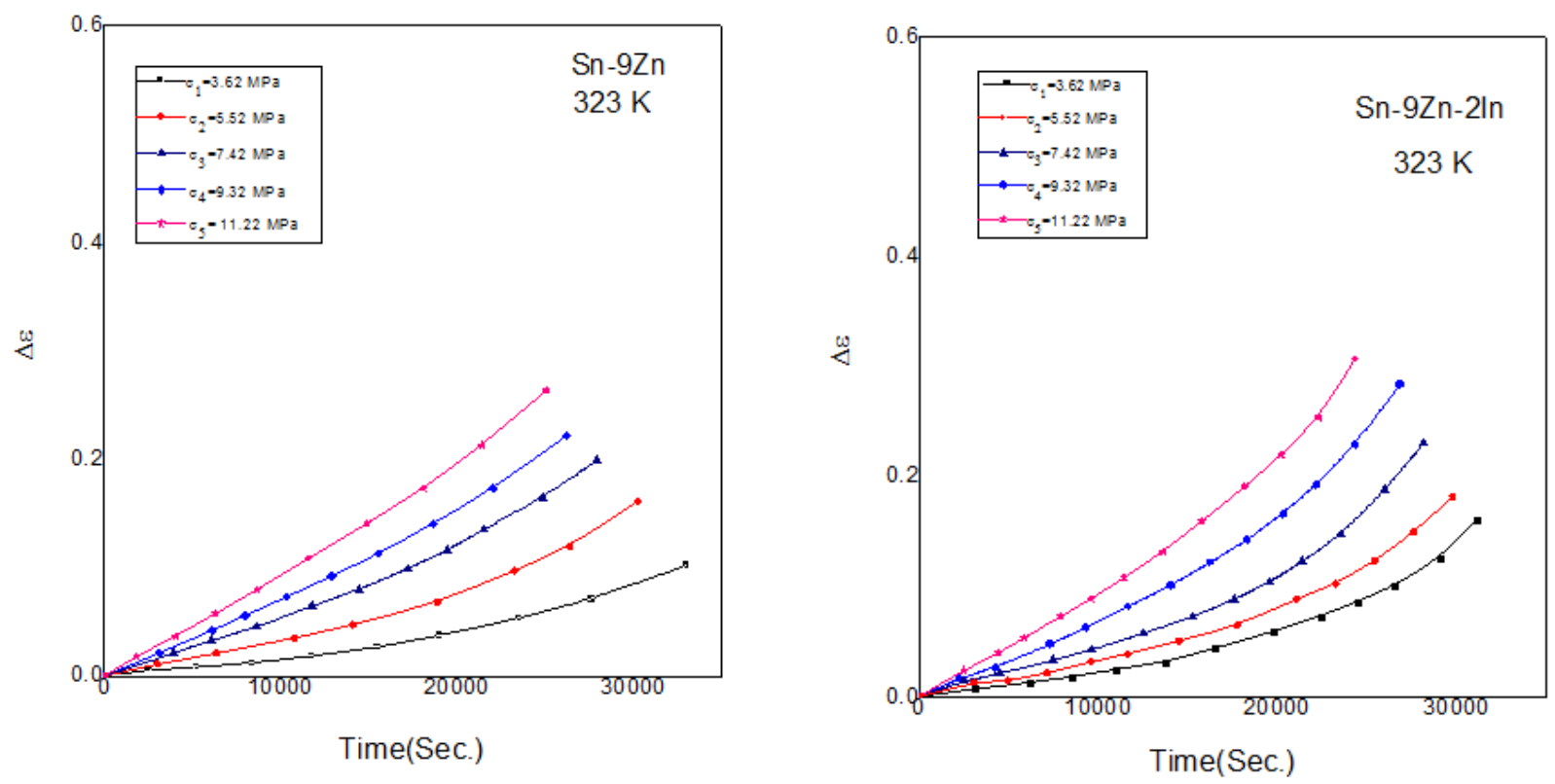

Fig.1a: Isothermal Creep Curves at $323 \mathrm{~K}$, at different applied stresses for Sn-9Zn eutectic and Sn-9Zn-2In alloys
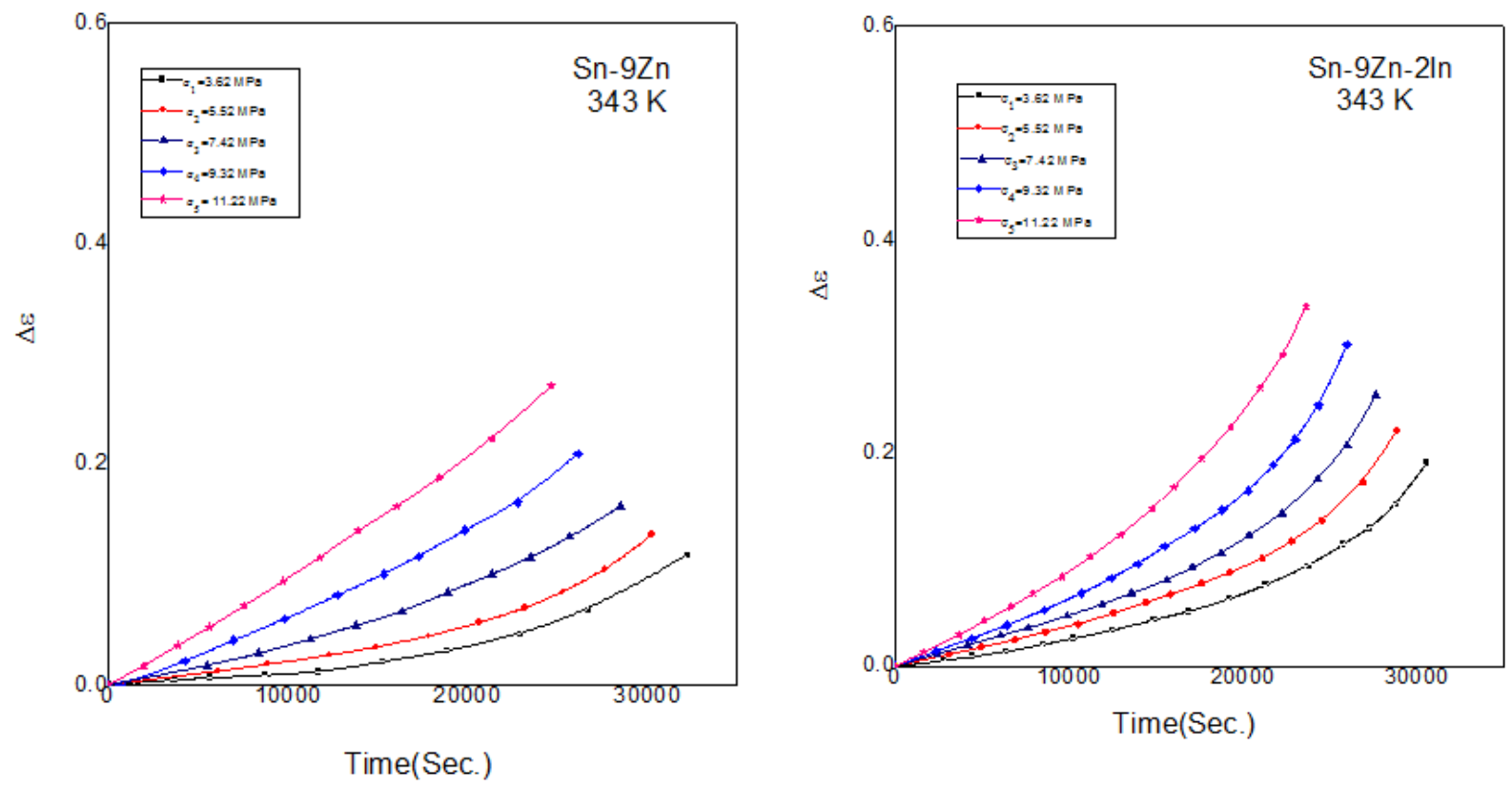

Fig.1b: Isothermal Creep Curves at $343 \mathrm{~K}$, at different applied stresses for Sn-9Zn eutectic and Sn-9Zn-2In alloys 

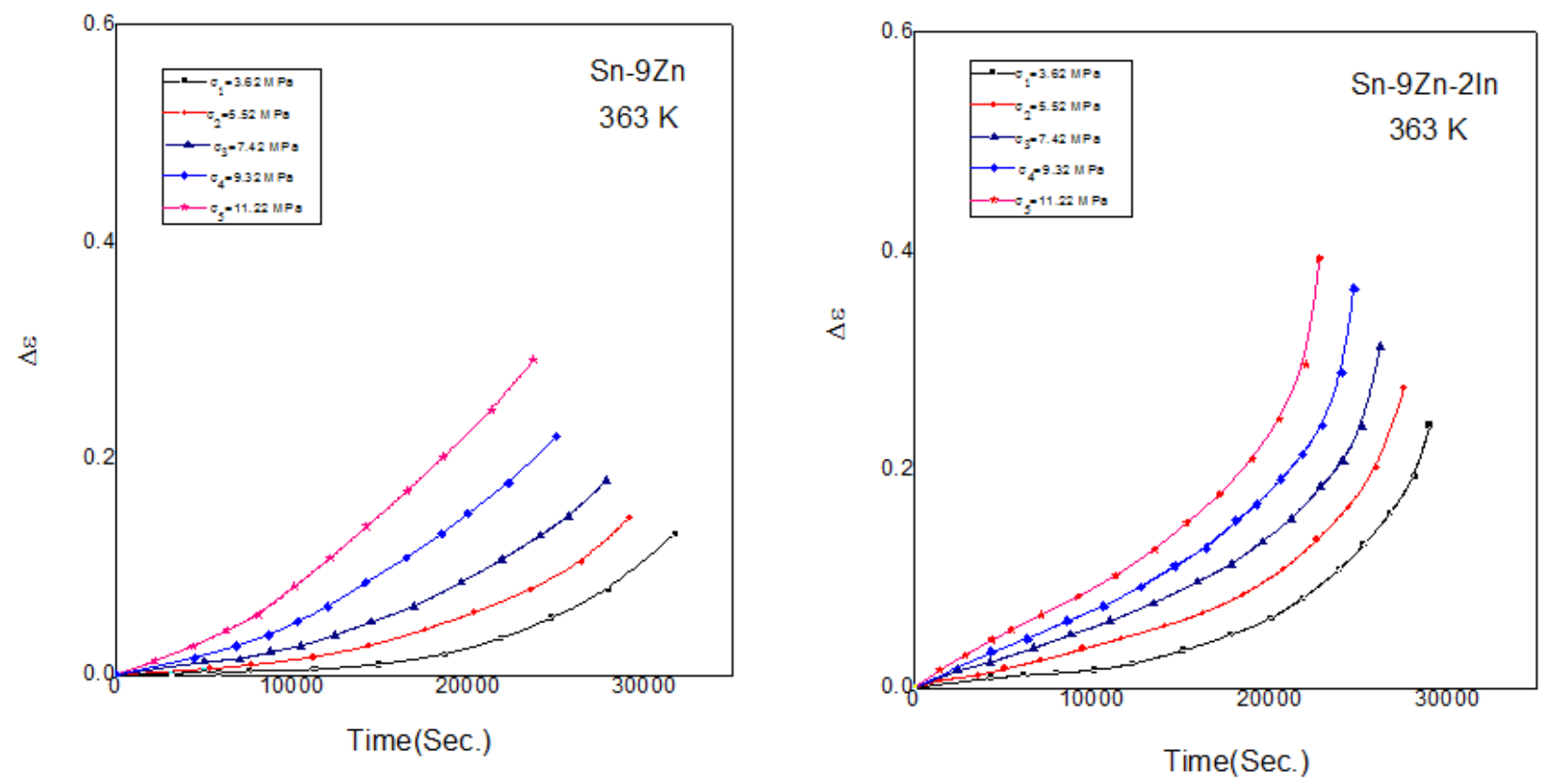

Fig.1c: Isothermal Creep Curves at $363 \mathrm{~K}$, at different applied stresses for Sn-9Zn eutectic and Sn-9Zn-2In alloys
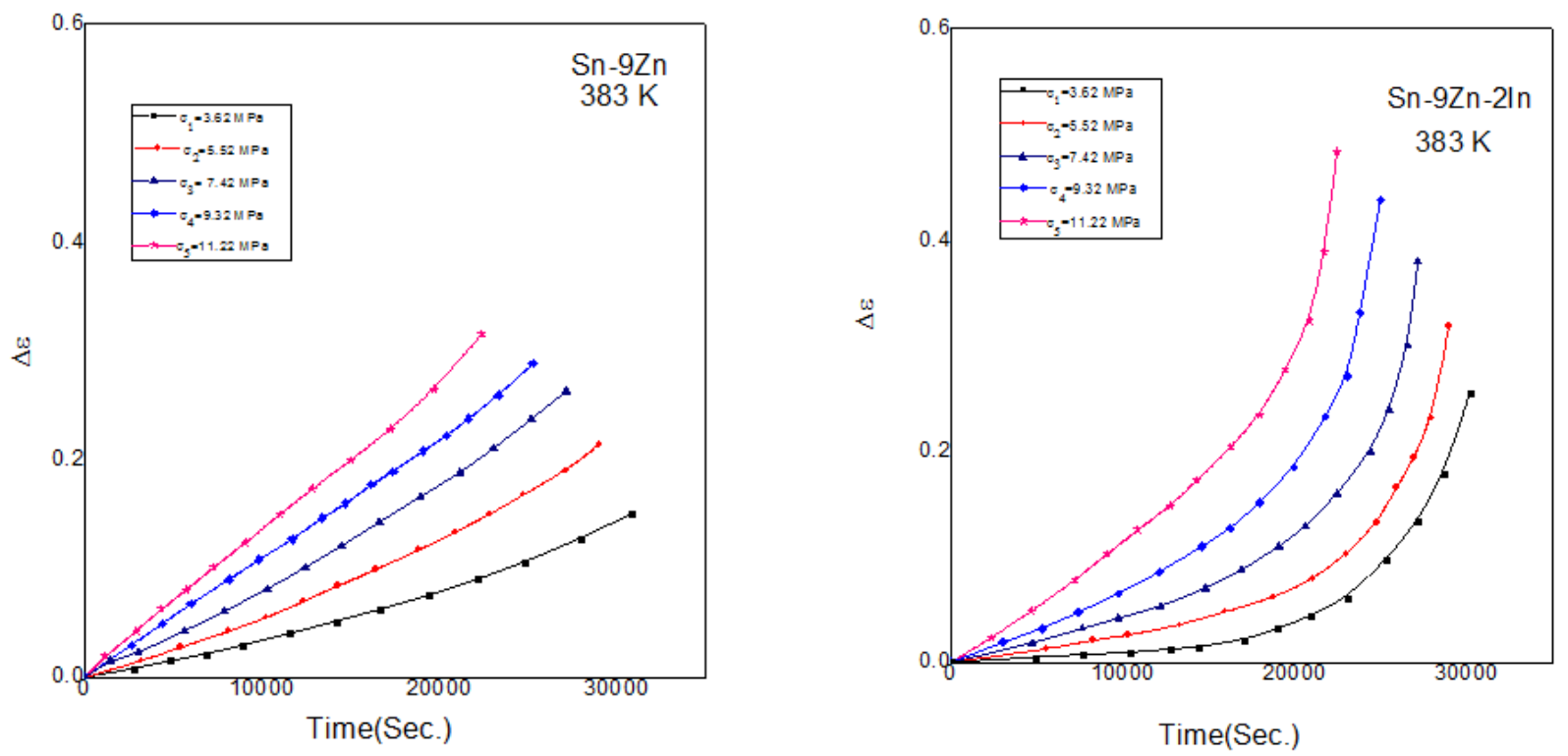

Fig.1d: Isothermal Creep Curves at $383 \mathrm{~K}$, at different applied stresses for Sn-9Zn eutectic and Sn-9Zn-2In alloys 

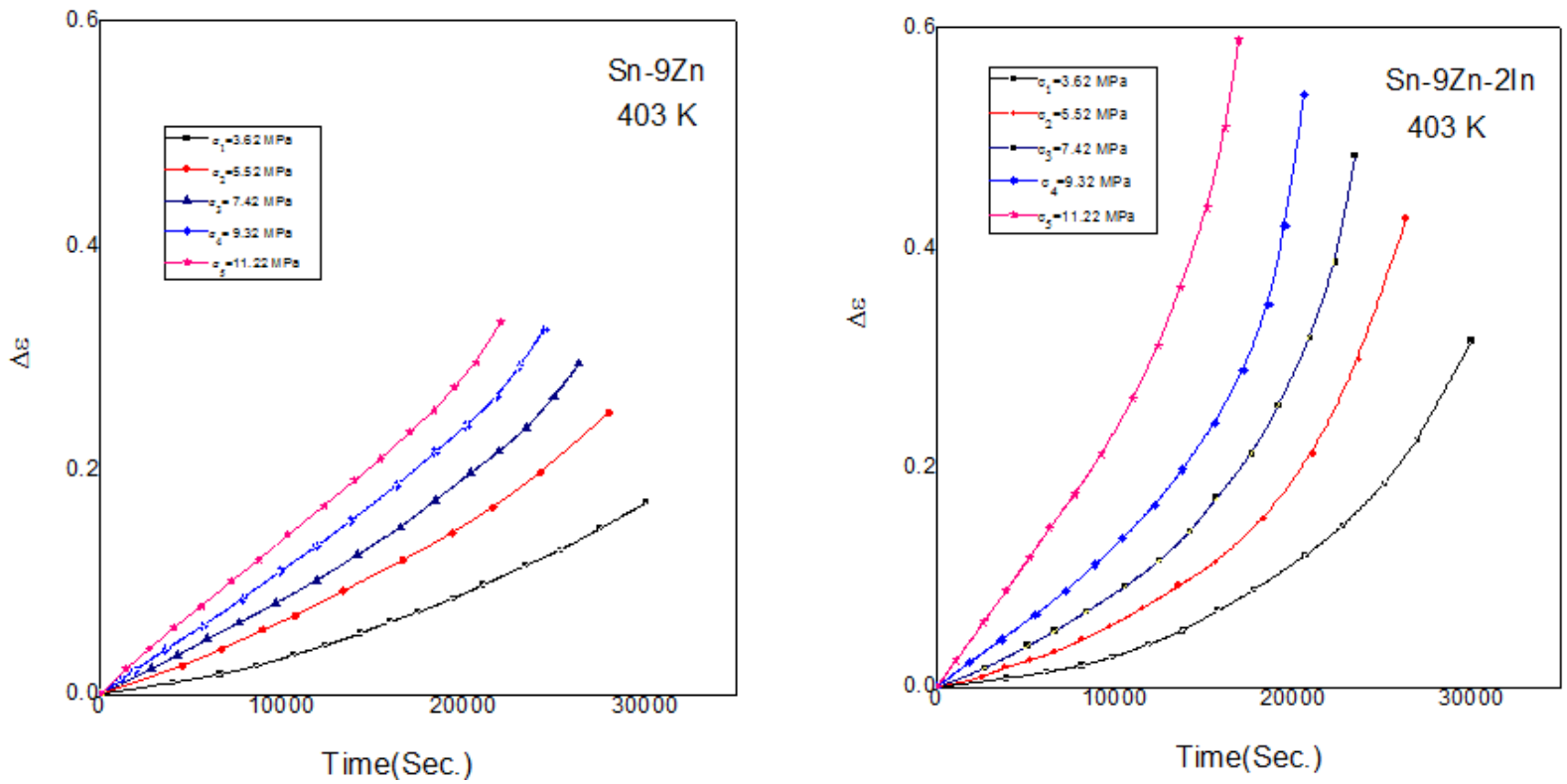

Fig.1e: Isothermal Creep Curves at $403 \mathrm{~K}$, at different applied stresses for $\mathrm{Sn-9Zn}$ eutectic and Sn-9Zn-2In alloys
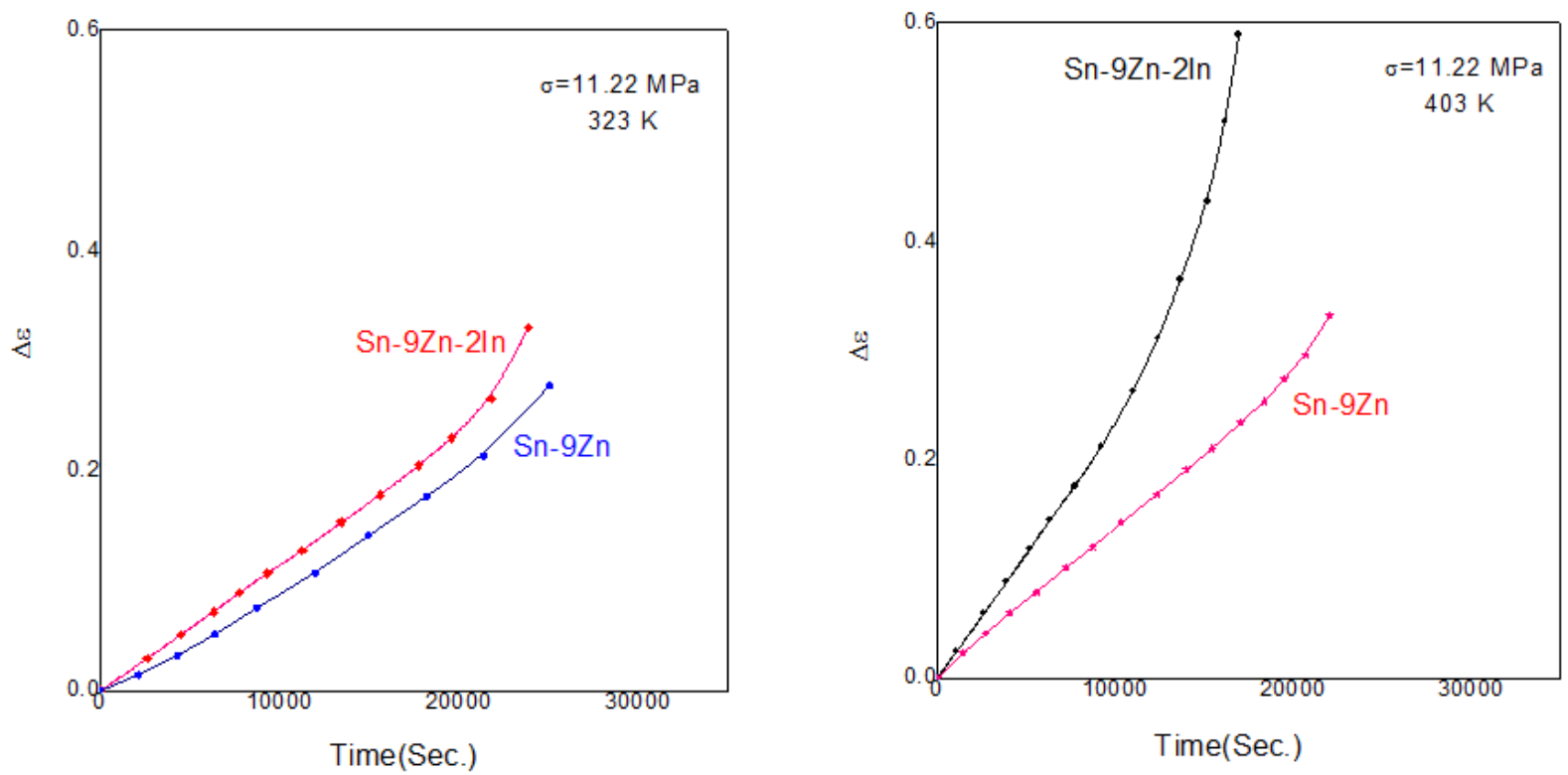

Fig.(2): Comparison on creep curves at $323 \mathrm{~K}$ and $403 \mathrm{~K}$, at stresses 3.62 and $11.22 \mathrm{MPa}$ for Sn-9Zn eutectic and Sn9Zn-2In ternary alloys 

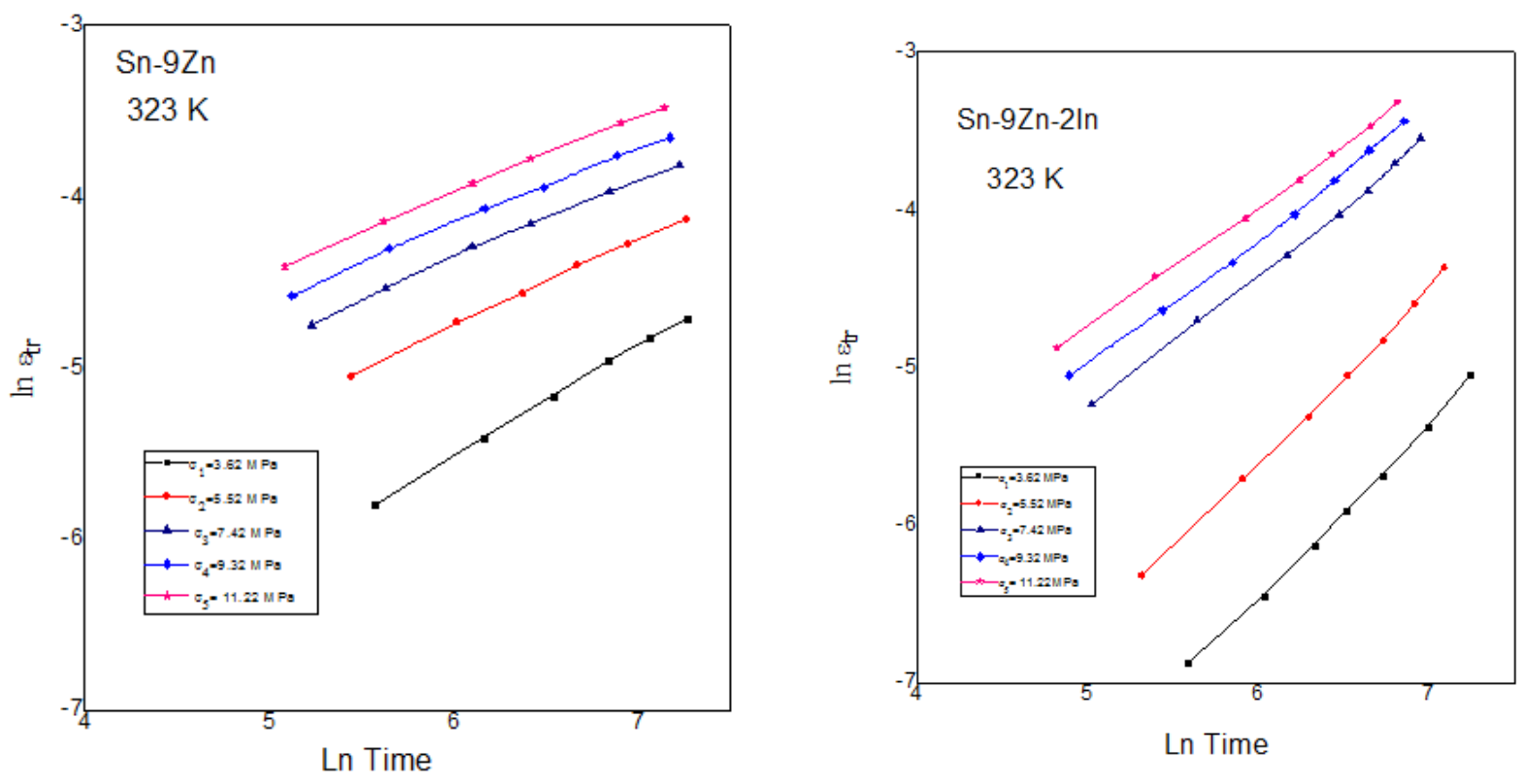

Fig. (3a): Relation between $\ln \varepsilon_{t r}$ and $\operatorname{lnt}$ for Sn-9Zn eutectic and Sn-9Zn-2In alloys, at $323 \mathrm{~K}$ and different stresses

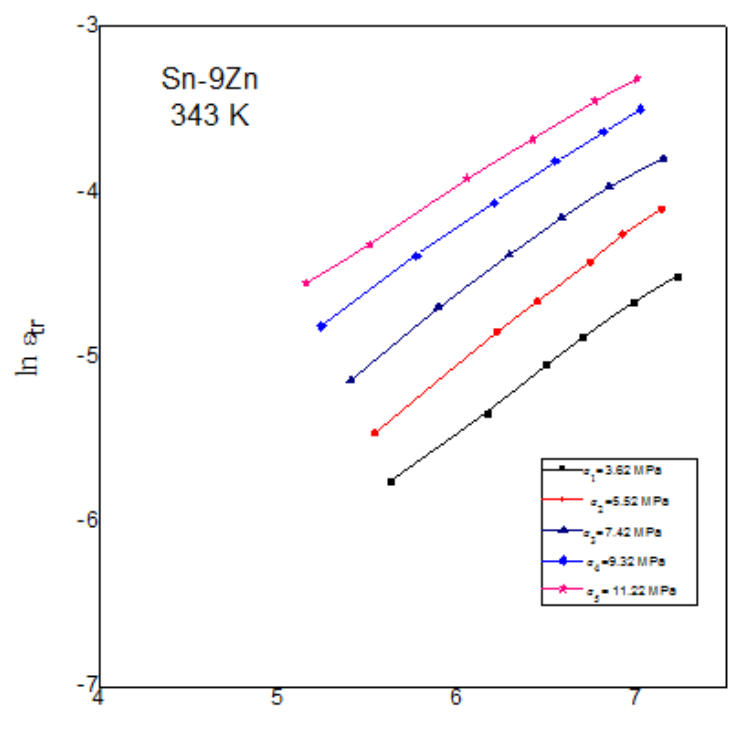

Ln Time

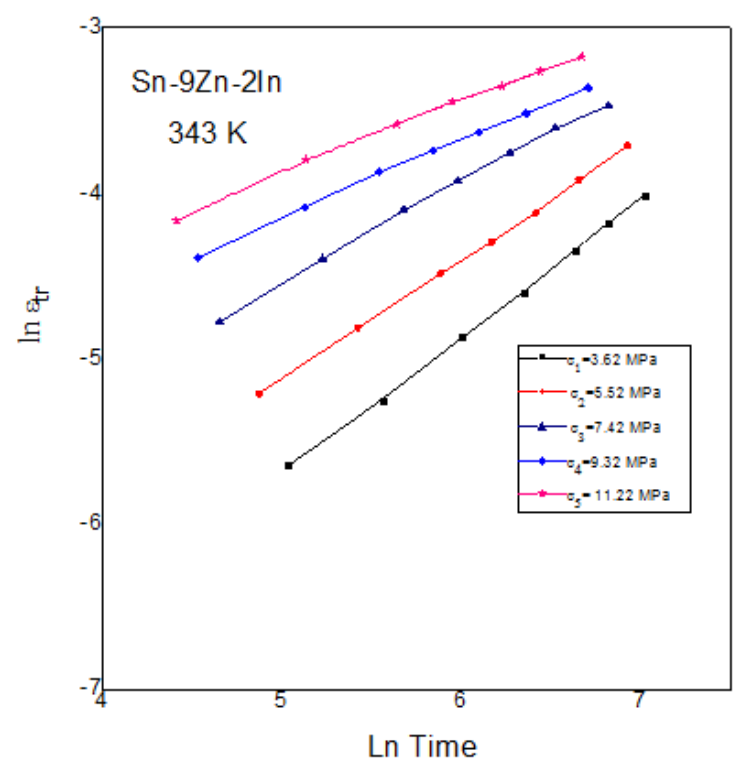

Fig. (3b): Relation between $\ln \varepsilon_{\mathrm{tr}}$ and $\operatorname{lnt}$ for $\mathrm{Sn-9Zn}$ eutectic and $S n-9 \mathrm{Zn}-2 \mathrm{In}$ alloys, at $343 \mathrm{~K}$ and different stresses 

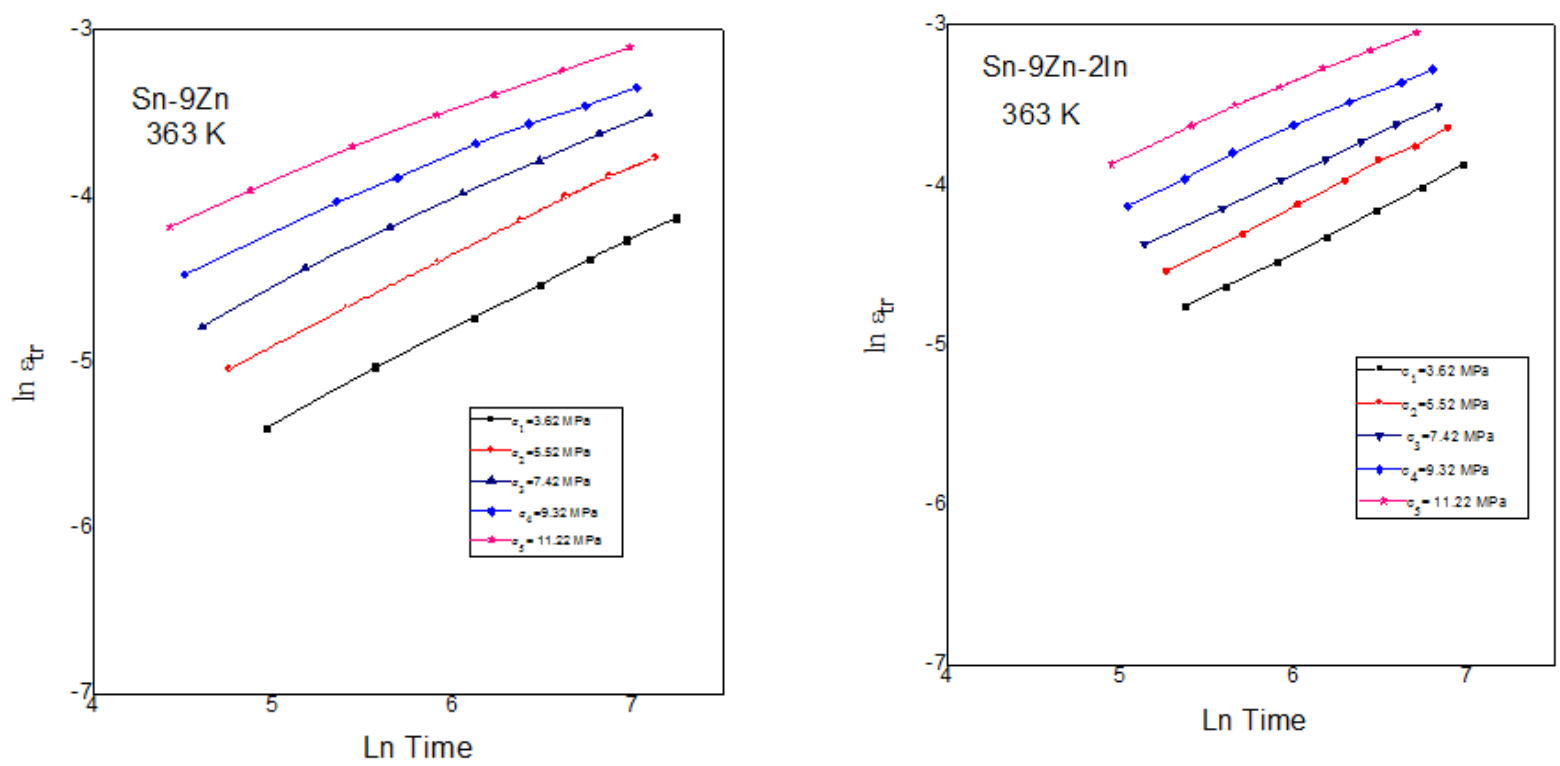

Fig.(3c): Relation between $\ln \varepsilon_{t r}$ and $\operatorname{lnt}$ for Sn-9Zn eutectic and Sn-9Zn-2In alloys, at $363 \mathrm{~K}$ and different stresses
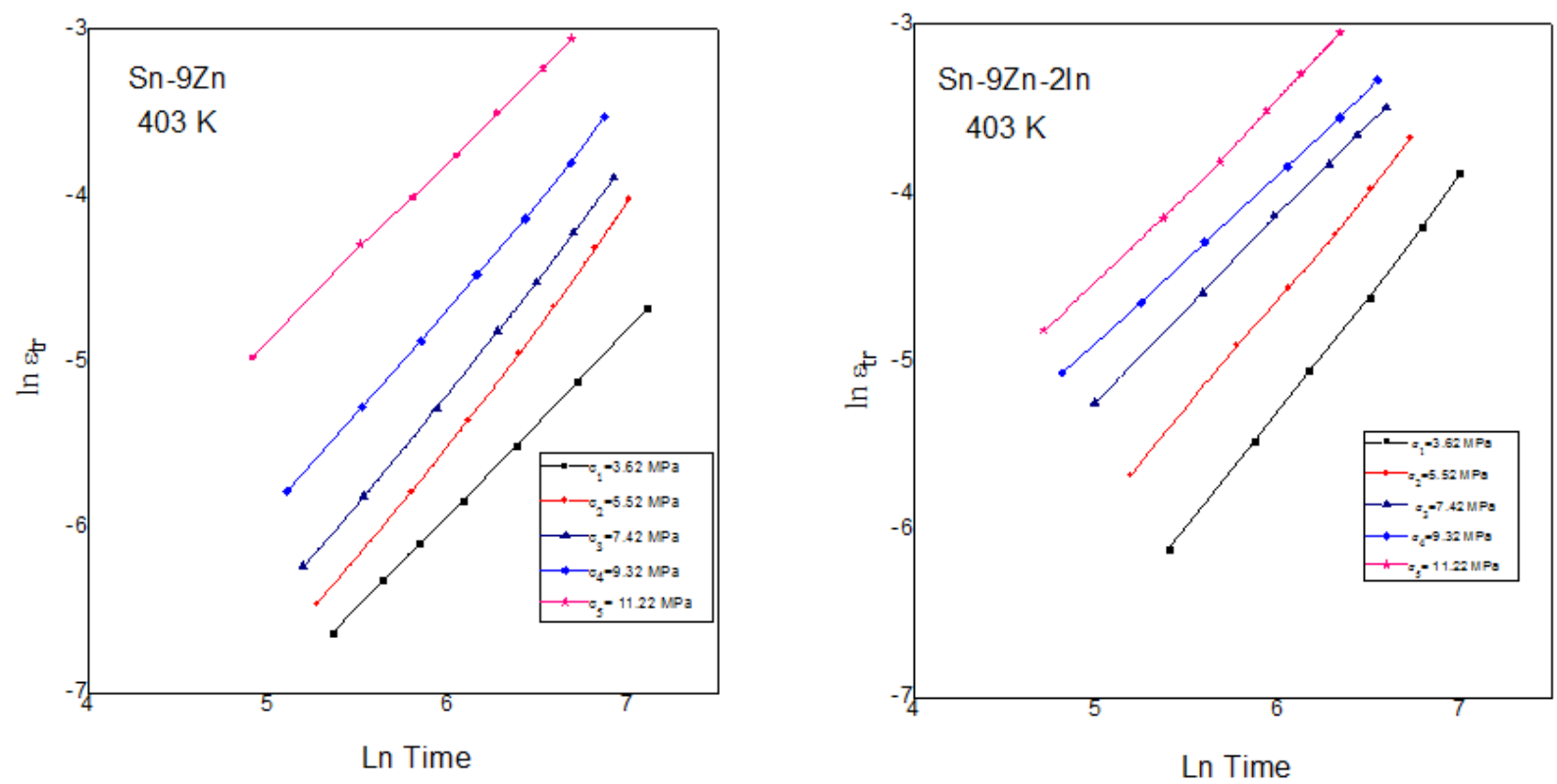

Fig. (3e): Relation between $\ln \varepsilon_{\mathrm{tr}}$ and $\operatorname{lnt}$ for $S n-9 \mathrm{Zn}$ eutectic and Sn-9Zn-2In alloys, at $403 \mathrm{~K}$ and different stresses 

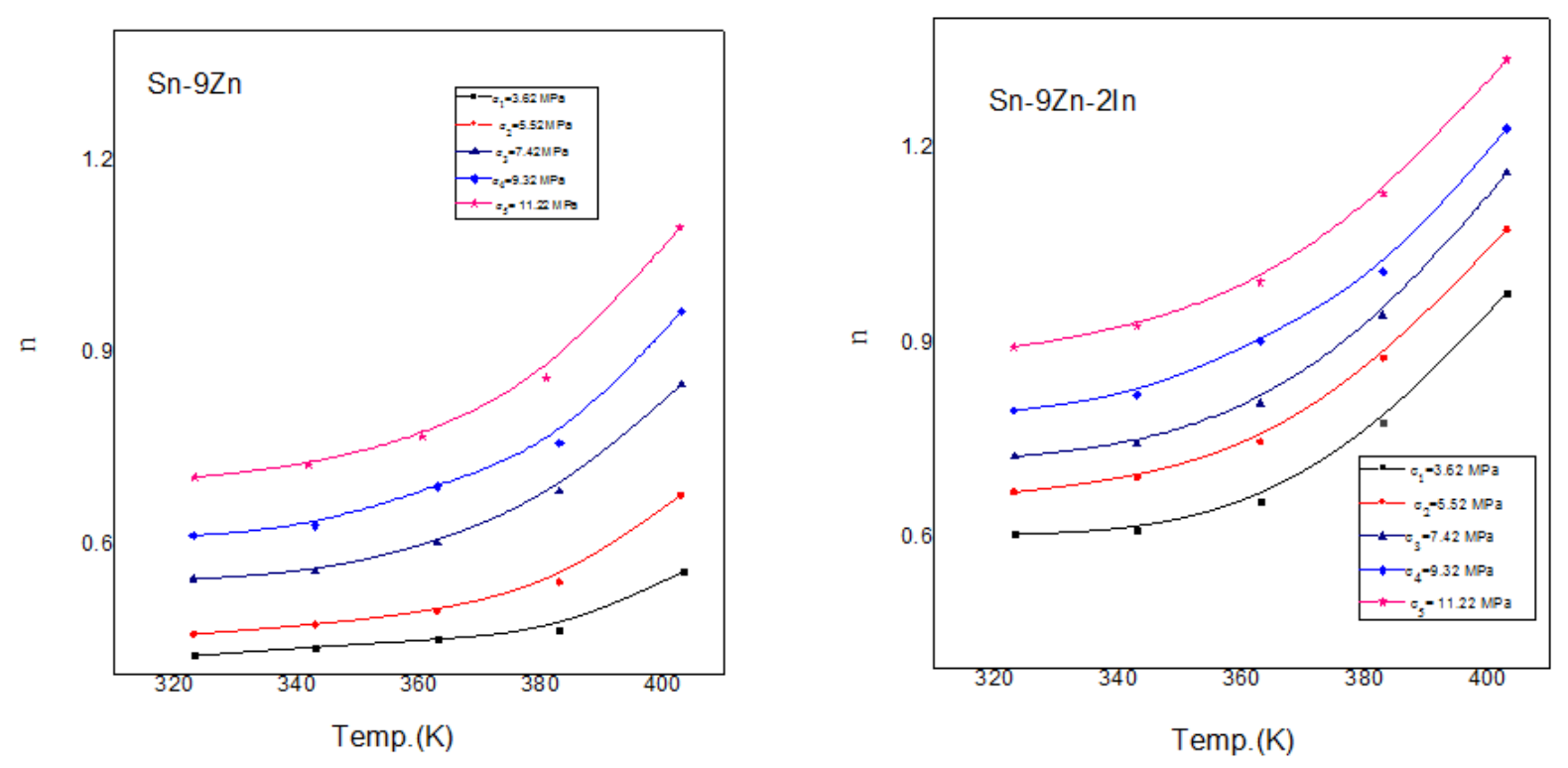

Fig.(4): The dependence of the parameters, $n$, on the working temperature at different applied stresses for Sn-9Zn eutectic and Sn-9Zn-2 I $n$ alloys
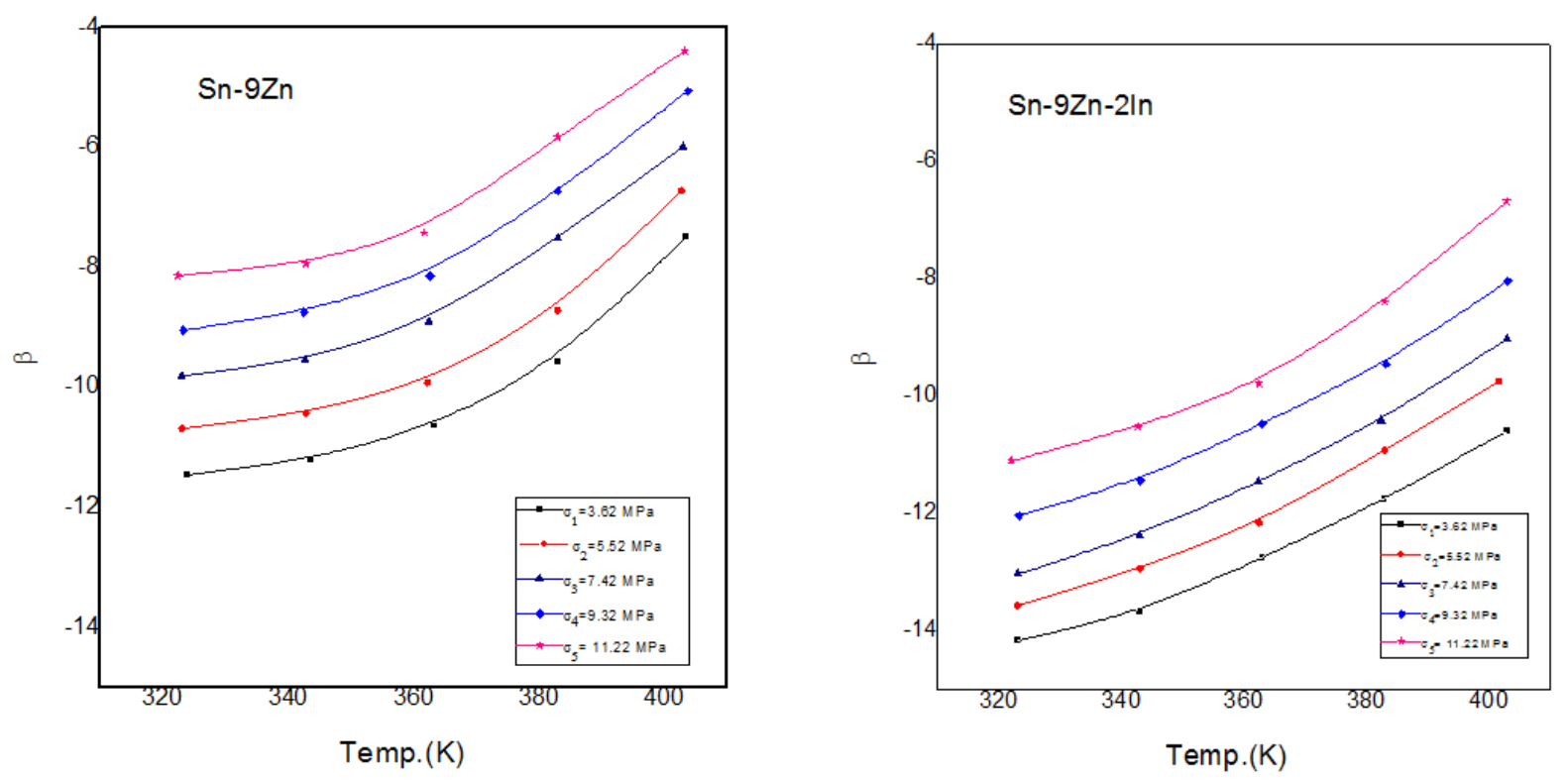

Fig(5): The dependence of the parameters, $\beta$ on the working temperature at different applied stresses for Sn-9Zn eutectic and Sn-9Zn-2 I $n$ alloys 

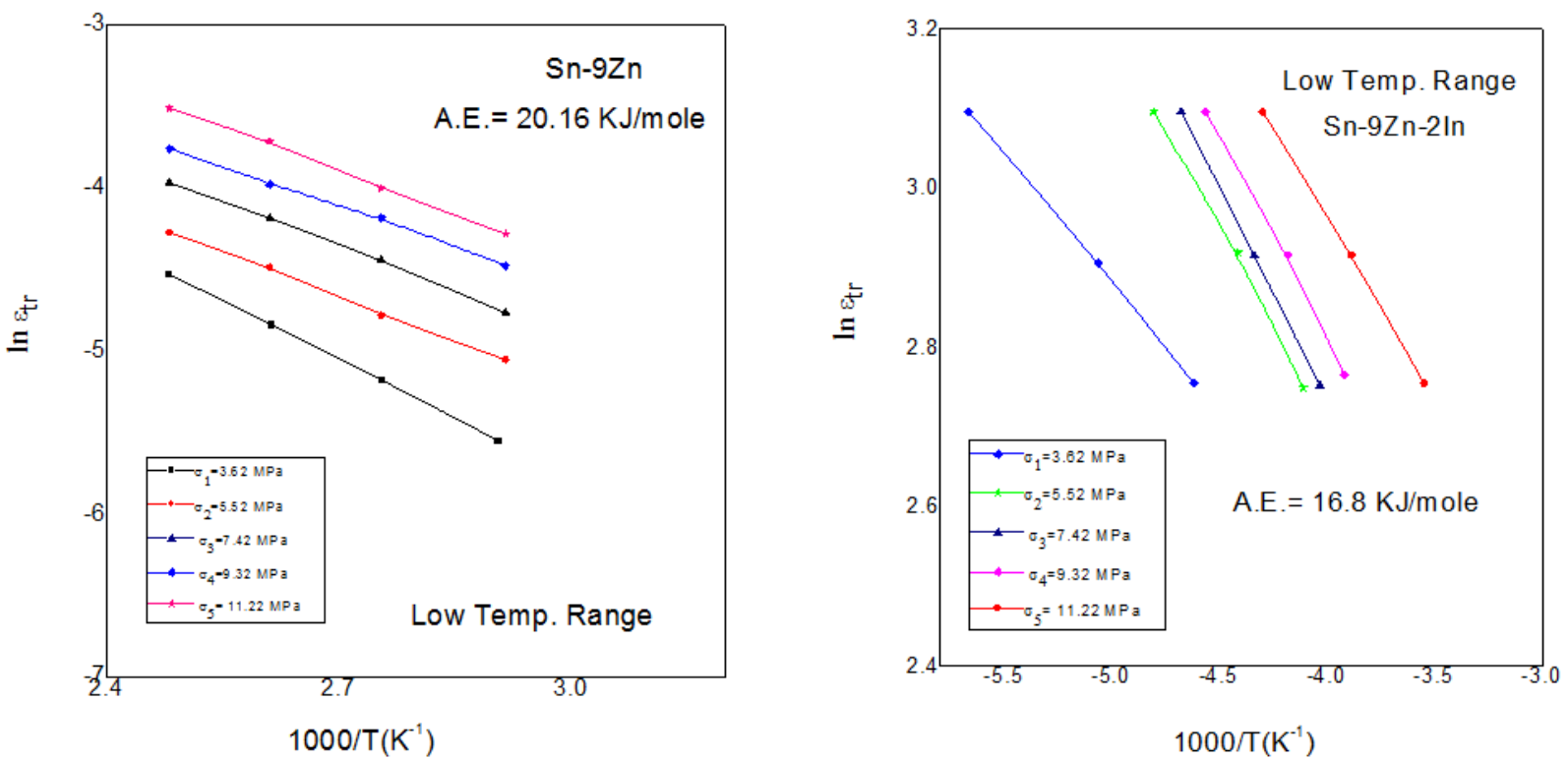

Fig.(6): The relation between $\operatorname{Ln} \varepsilon_{t r}$ and 1000/T at different applied stresses for Sn-9Zn eutectic and Sn-9Zn-2In alloys at low Temp
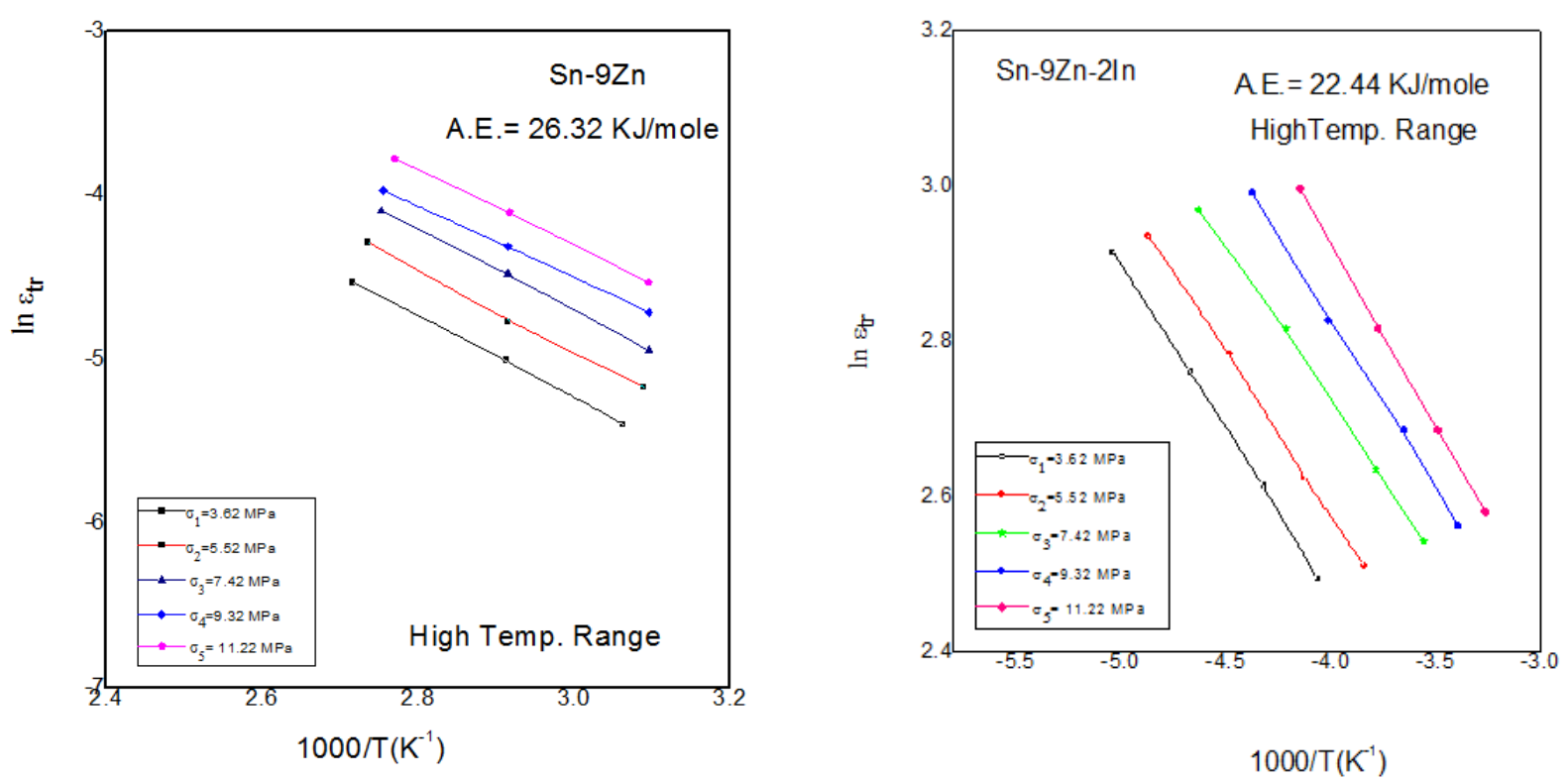

Fig.(7): The relation between $\mathrm{Ln} \varepsilon_{\mathrm{tr}}$ and 1000/T at different applied stresses for Sn-9Zn eutectic and Sn-9Zn-2 I $n$ alloys at high Temp 

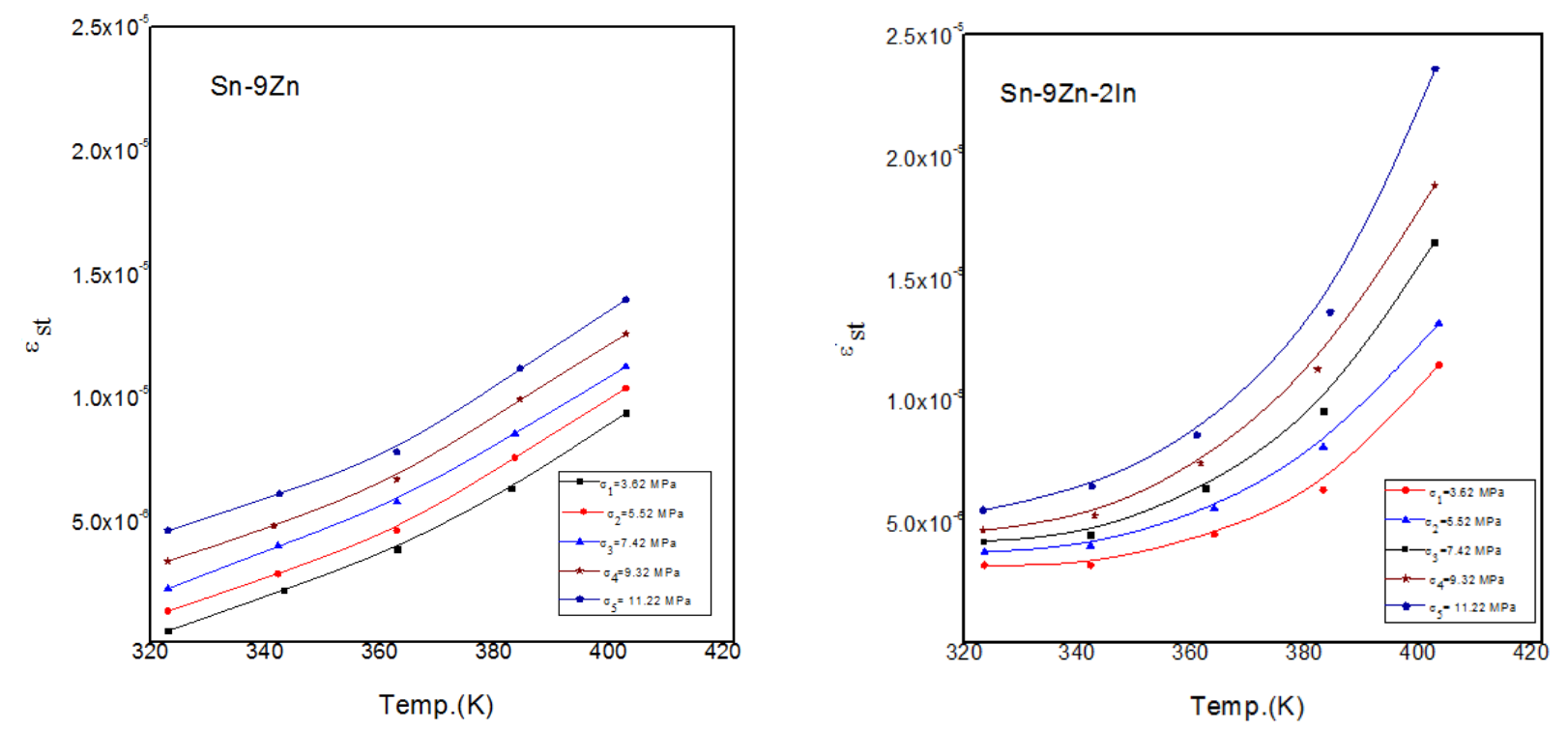

Fig.(8): Steady-state strain rate $\varepsilon_{\text {st }}^{\cdot}$ as a function of creep temperature for Sn-9Zn eutectic and Sn-9Zn-2 I $n$ alloys
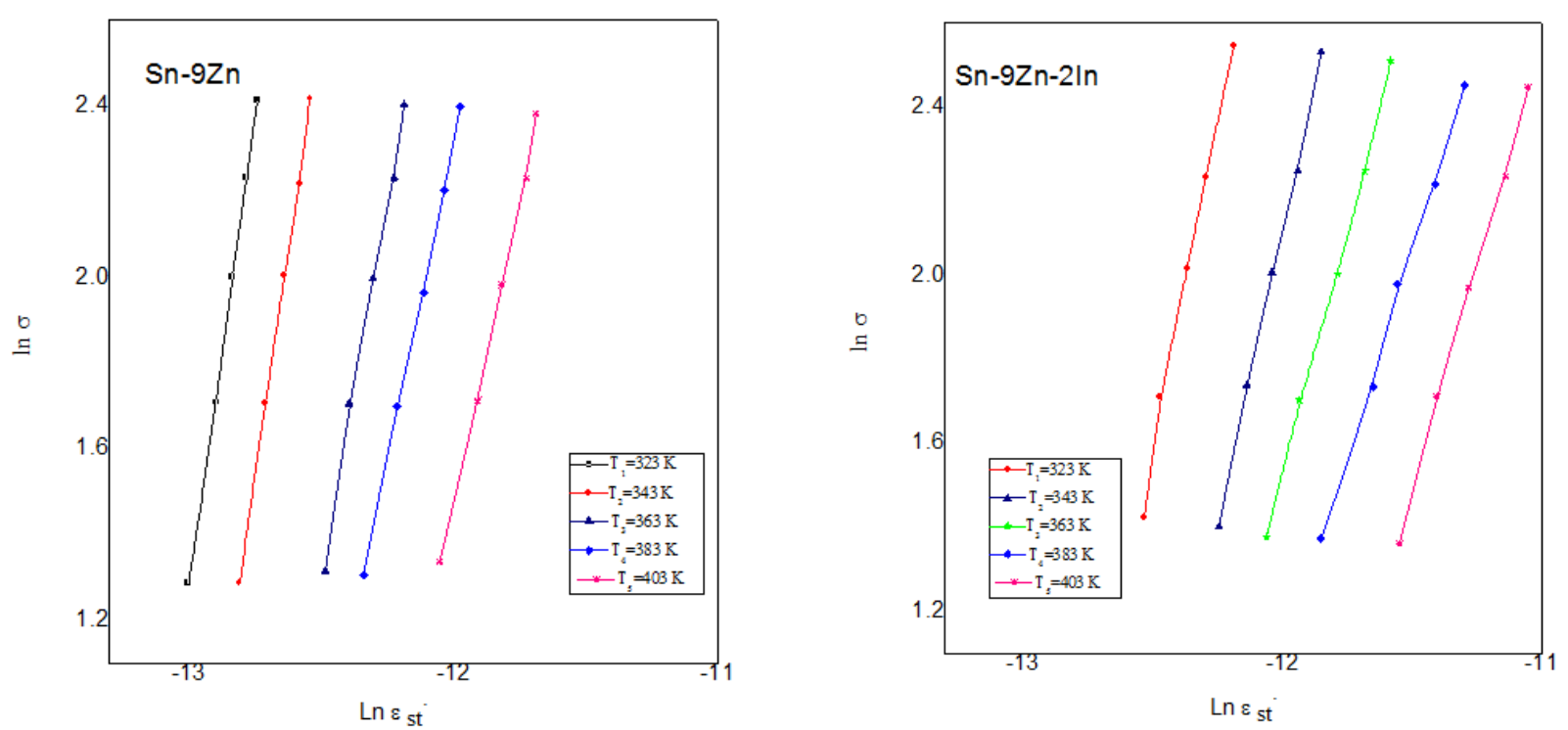

Fig.(9): Strain rate-stress relationship for Sn-9Zn eutectic and Sn-9Zn-2In alloys. 
Moreover, the acquired results verify the equation of steady state creep $[24,28,29]$.

$$
\varepsilon \cdot{ }_{s t}=c\left(\frac{\sigma}{d}\right)^{1 / m} \exp \left(\frac{Q}{k T}\right)
$$

where $m=0.5$ for dislocation ascent over grain boundaries [30] therefore, it is considered here that the higher elongation is attributed to the dislocation motion results in GBS and contained it during the deformation.

Creep is believe as a thermally stimulate process to make up energy losses which may happened as a result of the presence of definite defects and their interaction with the stress-induced non resonant bowing of dislocation segments [26]. This consideration is consistent with the increasing value of the total creep strain (ctot ) and the corresponding activation energy $Q$ obtained at higher working temperature and stress see $\mathrm{Eq}(4)$.

$\varepsilon_{\text {tot }}=\mathrm{A} \sigma^{\mathrm{m}} \exp \{-\mathrm{Q} / \mathrm{RT}\}$

With $\varepsilon_{\text {tot }}$ the total strain rate (= total creep strain $\varepsilon_{\text {tot }}$ / fracture time $t_{\mathrm{f}}$ ).

The exponent $\mathrm{n}$ was found to have values ranging from 0.428 to 1.094 for Sn-9Zn binary alloy, and from 0.6 to 1.33 for Sn-9Zn-2In ternary alloys. It was found that $\mathrm{n}$ increases with increasing deformation temperature and applied stresses for both alloys as shown in Fig.(4), the parameter $\beta$ was found to raise with rising temperature and applied stress as shown in Fig(5), it was found to exhibit values ranging from -11.46 to -4.93 for Sn9Zn binary alloy, and from -14.17 to -6.68 for Sn9Zn-2In ternary alloys as written in Table(1).
The transient creep is existence to be clear subject on the working temperature. The temperature dependence of the evaluated amount of $n$ and $\beta$ shows a sole transformation temperature below $363 \mathrm{~K}$. The strengthen in creep of the alloys above $363 \mathrm{~K}$ as spotted from the difference of the parameters $\mathrm{n}$ and $\beta$ below and above this temperature might be due to the increased mutual solubility of the ingredients phases above $363 \mathrm{~K}$. The spotted increase in $n$ and $\beta$, could be because of the variations in the microstructure of the phase due to the changes in their quantitative proportions [26].

The activation enthalpy of the transient creep $\mathrm{Q}_{\mathrm{tr}}$ was calculated using the following equation [31]:

$$
\varepsilon_{\mathrm{tr}}=\varepsilon_{0}+\mathrm{t}^{\mathrm{n}} \exp \left\{-\mathrm{Q}_{\mathrm{tr}} / \mathrm{KT}\right\}
$$

where $\varepsilon_{0}$ is the instantaneous strain.

These results yield activation enthalpies of 20.16 and $26.32 \mathrm{KJ} / \mathrm{mole}$ for Sn-9Zn eutectic in low and high temperature regions. The activation enthalpies for Sn-9Zn-2In alloys were 16.8 and 22.44 $\mathrm{KJ} / \mathrm{mole}$ in low and high temperature regions as shown in Table1. It is clear that activation enthalpies for Sn-9Zn binary alloys are more than ternary Sn-9Zn-2In alloys in low and high temperature regions because of ternary alloys are more refine in grain size and superplastic than binary alloys. The activation enthalpies, point that the transient creep in the down temperature zone is controlled by dislocation intersection, while at elevation temperatures, creep is concerted by grain boundary sliding [26].

Table (2): Comparison of the transient creep characteristics of the tested alloys

\begin{tabular}{cccc}
\hline \multicolumn{1}{c}{$\mathrm{n}$} & $\beta$ & $\mathrm{Q}$ \\
\hline Materials & & & \\
\hline Sn-9Zn & $0.428: 1.094$ & $-11.46:-4.93$ & $20.16: 26.32$ \\
Sn-9Zn-2In & $0.60: 1.33$ & $-14.17:-6.68$ & $16.8: 22.44$
\end{tabular}

The steady-state strain rate $\dot{\varepsilon}_{\text {st }}$ of the tested samples is calculated from the slopes of the linear parts of the obtained creep curves Fig.(1a-e). It rises with rising the temperature and stress in two alloys as shown in Fig.(8). It can be seen that at the same test properties the Sn-9Zn-2In alloy 
showed higher strain rate $\varepsilon$ 'st compared with that of the Sn-9Zn one. It can be shown that each curve is described by three particular regions: (I) primary, (II) secondary or steady state, and (III) tertiary. Since the temperature and pressure are stable, the difference in creep rates, $\varepsilon^{\circ}$, proposes a basic variation in the internal structure of the alloy during time. The strain $\varepsilon$ and strain rate $\varepsilon^{\cdot}$ are, in general, lower for Sn-9Zn eutectic samples than for Sn-9Zn-2In samples in spite of the applied stress, because of refine the grain size of the ternary. Such differences in the creep behaviour may be related to the difference in the grain size between the two alloys. This result, together with the fact that no temperature dependence of strain at the low creep rate, proposes that the creep manner is highly influenced by the In addition. Furthermore, the gained low creep rates are not influenced by the creep weakening factor of dynamic recrystallization [32].

The differences in creep rate, $\varepsilon^{*}$, propose a requisite variation in the internal resistance stress of the used sample during time. This proposes that the hardening of the matrix was recovered at once and fixed at a widened distortion rate [33].

The variation of the transient creep parameter $\ln \sigma$, (where $\sigma$ is the stress) with the steady state creep $\ln \varepsilon_{\text {st }}^{\prime}$ for different applied stresses for Sn-9Zn eutectic and Sn-9Zn-2In alloys is represented in Fig.(9). The value of strain rate sensitivity parameter $m$ estimated from the slopes of these straight lines, and was found to have values ranging from 0.24 to 0.364 for Sn-9Zn binary alloy, and from 0.314 to 0.532 for Sn-9Zn-2 In ternary alloys as shown in Fig.(10). It is shown that the value of $m$ for Sn-9Zn-2 In ternary alloys is higher than that of Sn-9Zn binary alloy, interpreting that the sensitivity parameter $m$ for both alloys is temperature dependent. The excess of strain rate sensitivity parameter with temperature is in conformity the result of the alloys. The amount of $m$ shows that the commanding mechanism in the low temperature region is dislocation glide, while in the high temperature region the dominating mechanism is dislocation climb [34].

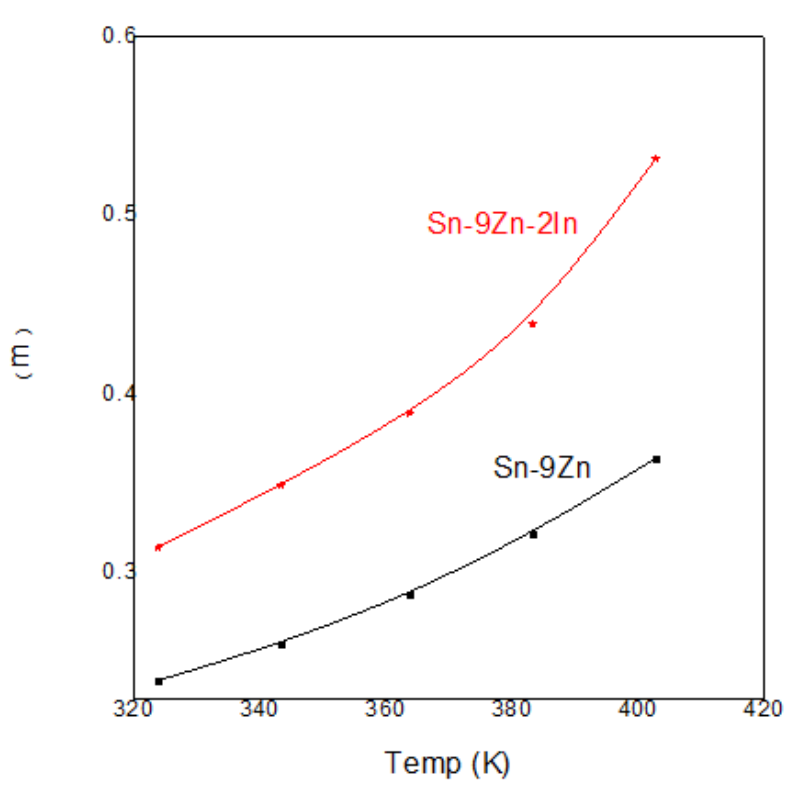

Fig.(10): Strain rate sensitivity parameter $m$ as a function of creep temperature Sn-9Zn eutectic and Sn-9Zn-2In alloys

It is commonly well recognized that the inner structure of an alloy domination and modifies the nature and mode of interaction of the existing disorder and the alloy composition. So, the extreme significant conclusion of the creep tests is the enormous reliance of the creep parameters on the micro-structural changes as well as the mix element [24].

On the basis of this statement, the difference in the strengths between the constituent phases can cause simultaneous change in the internal stress.

The activation energy of steady creep at fixed stresses was estimated using equation (4). The activation energy of steady state creep was calculated from the relation between $\ln \varepsilon_{\text {st }}$ and $1000 / \mathrm{T}$ at low and high temperature for Sn-9Zn eutectic and Sn-9Zn-2In alloys for five different applied stresses. The activation energies for the binary eutectic and ternary alloys have been found to be $26.31: 30.82$ and 23.36: $27.13 \mathrm{~kJ} \mathrm{~mol}^{-1}$ in the low and high temperature zone, respectively see Fig.(11,12); it is clear that activation enthalpies for Sn-9Zn binary alloys are more than

ternary Sn-9Zn-2In alloys in low and high temperature regions see Table (3). 

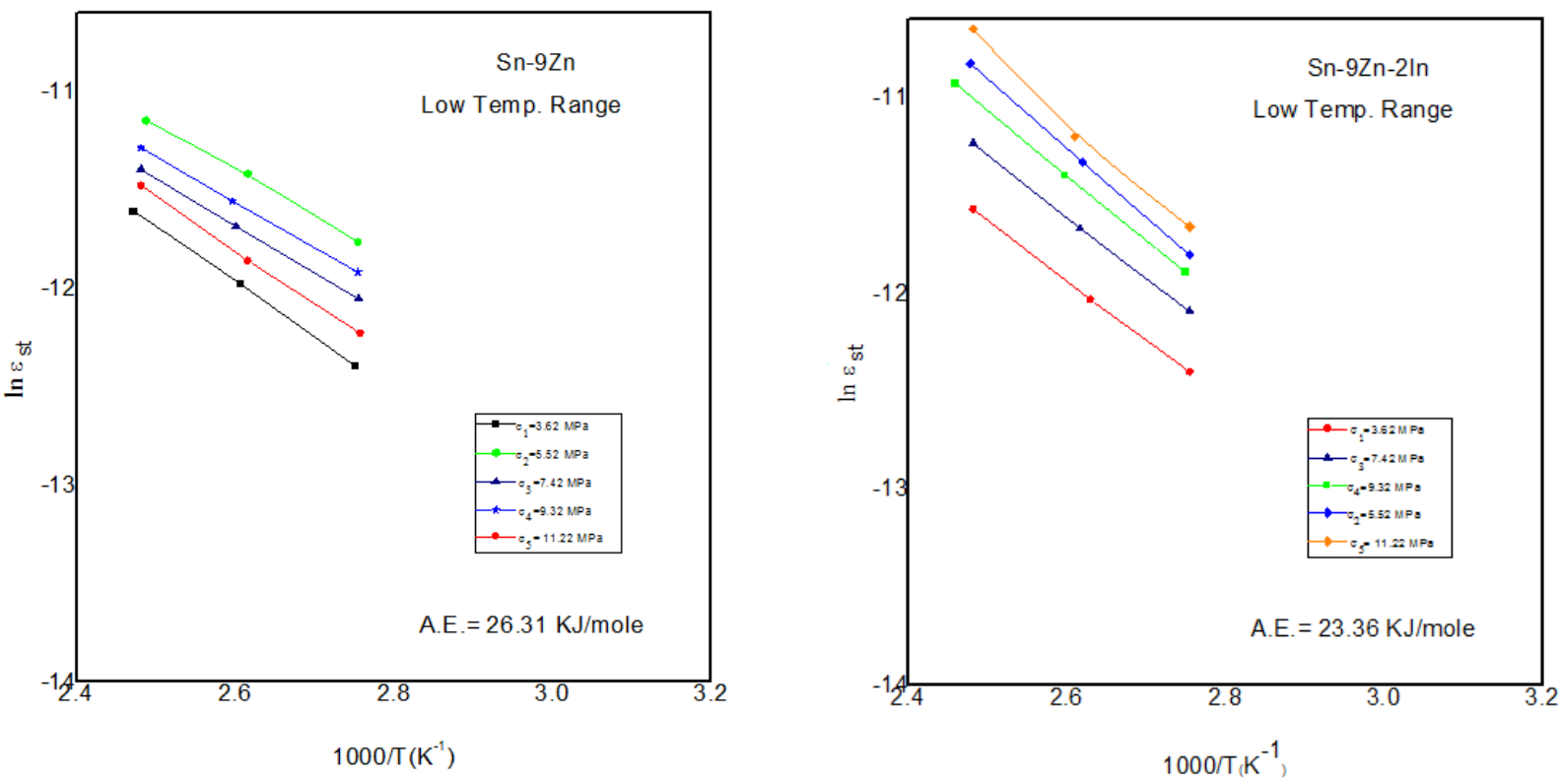

Fig.(11): The relation between $L n \varepsilon_{\text {tr }}$ and 1000/T at different applied stresses for Sn-9Zn eutectic and Sn-9Zn-2 I n alloys at low Temp.
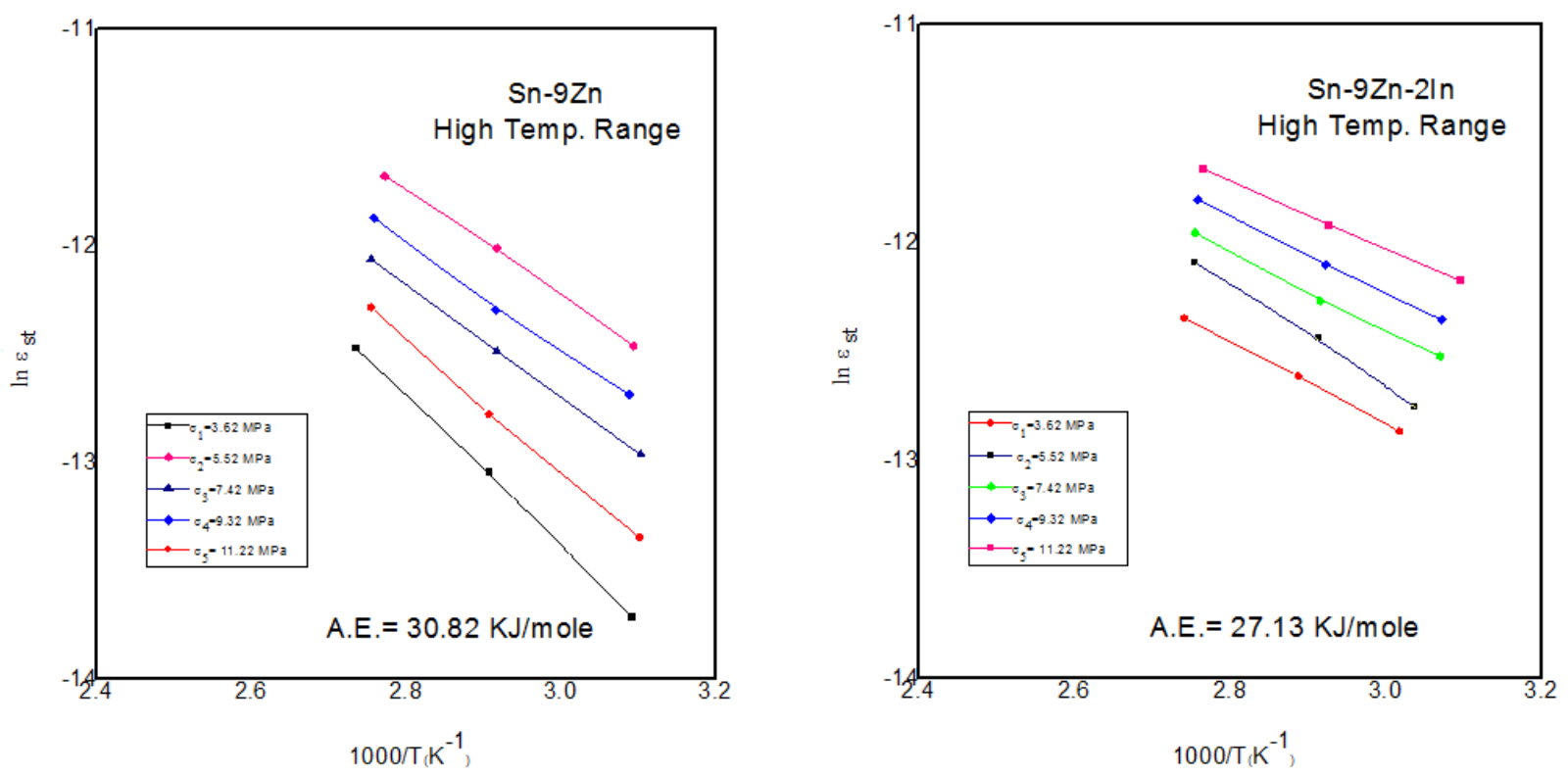

Fig.(12): The relation between $L n \varepsilon_{\text {tr }}$ and 1000/T at different applied stresses for $\mathrm{Sn-9Zn}$ eutectic and Sn-9Zn-2 I $n$ alloys at low Temp.

Table (3): Comparing of the steady state creep features of the tested alloys

\begin{tabular}{cccc}
\hline Materials & $(m)$ & $\varepsilon_{\text {st }}^{\prime}$ & Q \\
\hline Sn-9Zn & $0.24: 0.364$ & $5.52^{*} 10^{-7}: 1.39 * 10^{-5}$ & $26.31: 30.82$ \\
Sn-9Zn-2In & $0.314: 0.532$ & $3.29 * 10^{-6}: 2.36 * 10^{-5}$ & $23.36: 27.13$ \\
\hline
\end{tabular}


Fig.(13) represented the OM photograph of the two alloys in Fig.(13a), a typical eutectic Sn-9Zn microstructure composed of light gray areas of $\mathrm{Sn}_{5} \mathrm{Zn}_{8} \quad$ IMCs and dark network-like eutectic regions of $\beta$-Sn grain boundaries. In Fig.(13b), the appropriate content of In in the Sn-9Zn solder results in significant increase in ductility and was found to be enhancing the plasticity of the ternary alloys, this behaviour was attributed to refine the coarse needle-like Zn-rich phase and formation of intermetallic compounds (IMCs) and, $\gamma$-In $\mathrm{Sn}_{4} \quad$ which improve the microstructure of the alloy. Consequently, the mechanical properties of Sn-9Zn-2In solder may be enhanced.
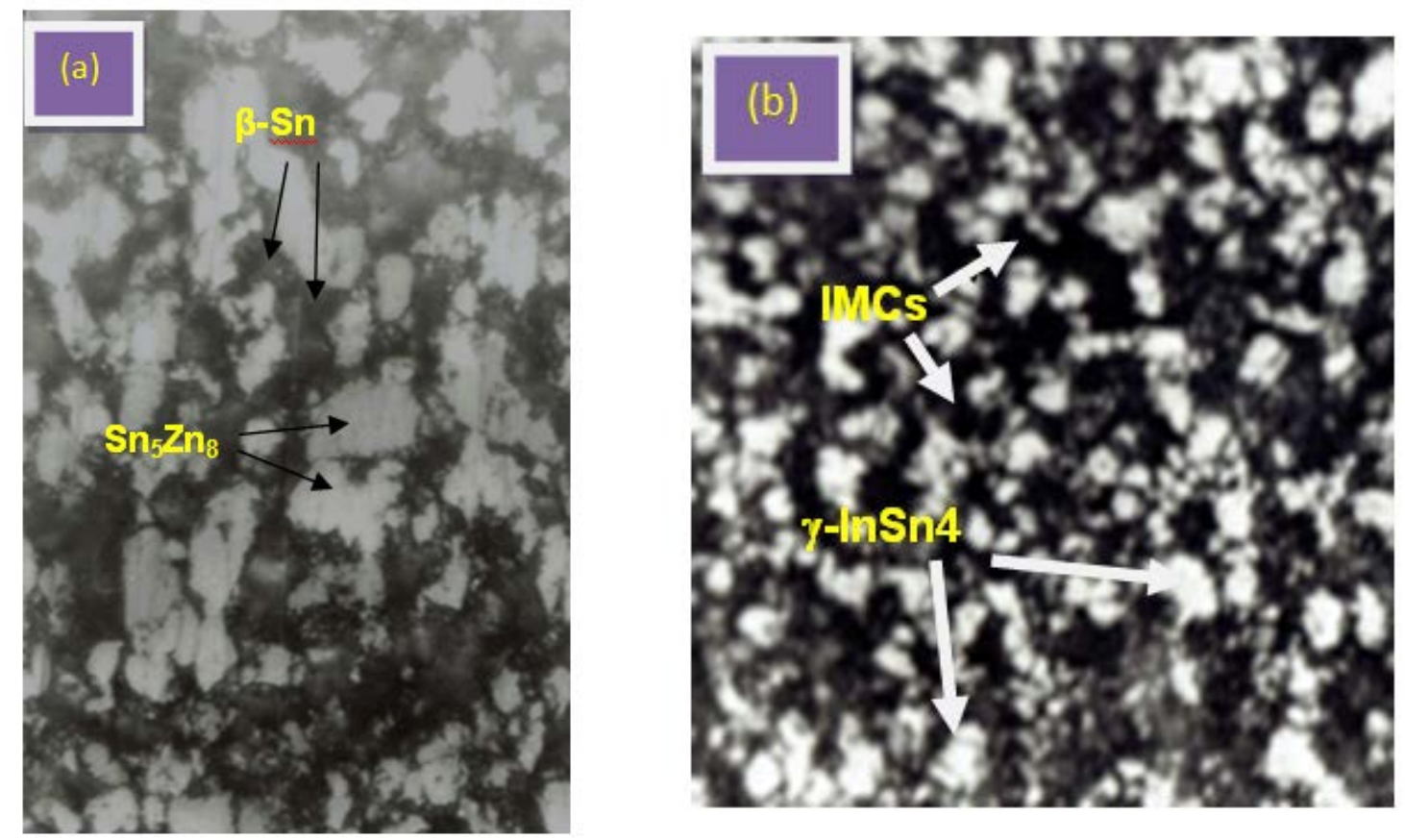

Fig.(13) illustrates the OM images of the two alloys in Fig.13a, a typical eutectic Sn-9Zn microstructure composed of light gray areas of $\mathrm{Sn}_{5} \mathrm{Zn}_{8}$ IMCs and dark network-like eutectic regions of $\beta$-Sn grain boundaries. In Fig.13b, the OM images become refine and formation of intermetallic compounds (IMCs) and, $\gamma$-In Sn ${ }_{4}$ happen; which improve the microstructure of the alloy

Fig.(14) displays the XRD scans of the deformed Sn-9Zn and Sn-9Zn-2In experimental alloys. In general, all the as-cast experimental alloys are mainly composed of $\beta$-Sn phase and precipitated $\mathrm{Sn}_{5} \mathrm{Zn}_{8}$ phase. However, the alloys containing In exhibited additional IMCs such as $\gamma-\mathrm{In} \mathrm{Sn}_{4}$ and, $\beta$ $\mathrm{In}_{3} \mathrm{Sn}$. It is obvious that the Sn-9Zn alloy has two types of precipitates having various morphologies. The first one has a fixed network and the second has an isolated very fine particles-like shape.
According to the XRD the continuous precipitates are $\beta$-sn, phases while the fine particle precipitates are $\mathrm{Sn}_{5} \mathrm{Zn}_{8}$ IMCs. It is remarkable to note from Fig. (14b) that with adding 2In to the Sn-9Zn alloy, the morphology of the $\mathrm{Sn}_{5} \mathrm{Zn}_{8}$ phase in the alloy gradually changes from coarse precipitates to a relatively fine shape $\gamma-\mathrm{In} \mathrm{Sn}_{4}$. 

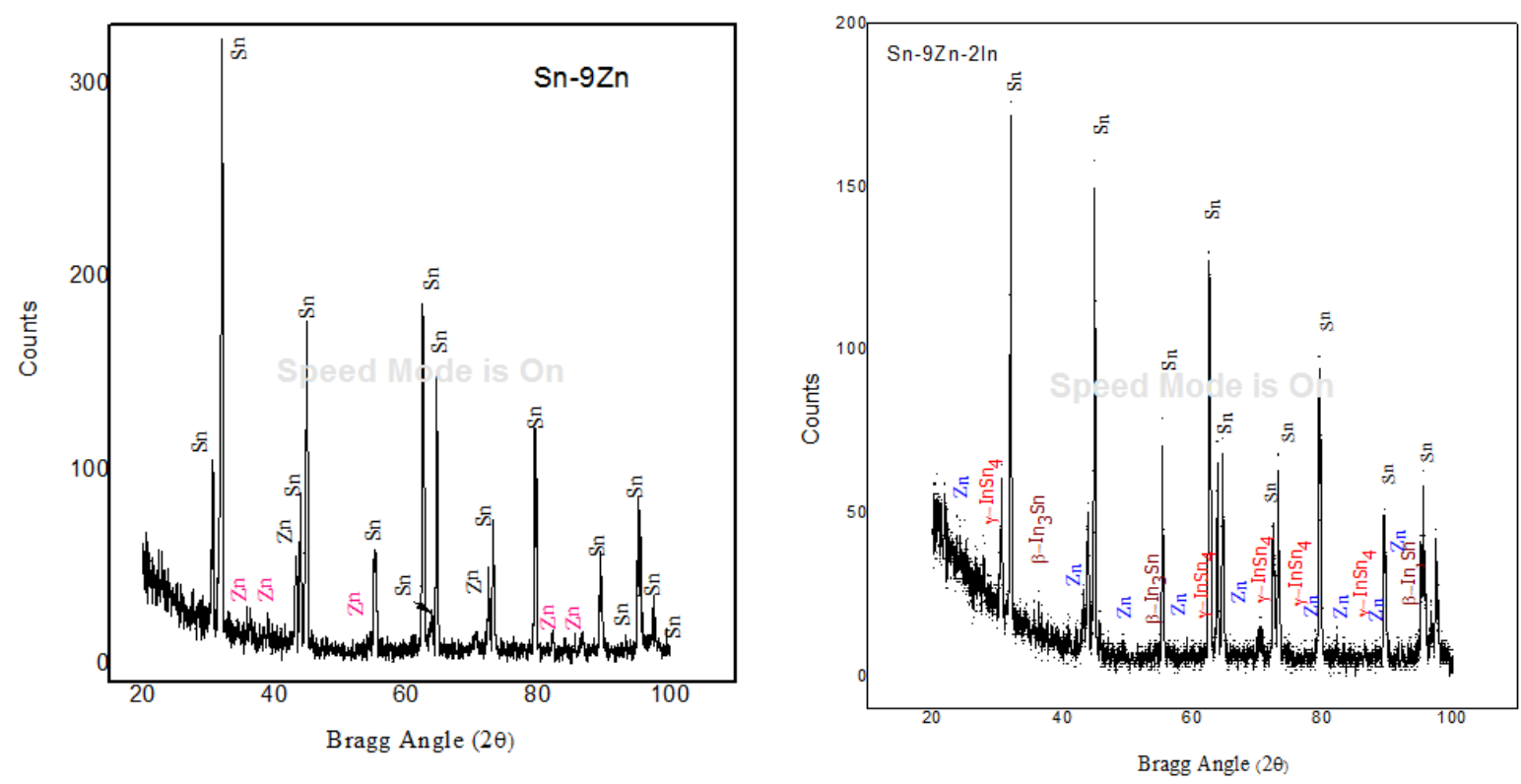

Fig.(14a): XRD $x$-ray diffraction analysis for $S n-9 Z n$ binary alloy are mainly composed of $\beta$-Sn phase and precipitated $S_{5} Z_{n_{8}}$ phase and; $b$, for Sn-9Zn-2In ternary alloys containing In exhibited additional IMCs such as $\beta$-In ${ }_{3} S n$ and $\gamma$-In $\mathrm{Sn}_{4}$

Fig.(15) shows Phase diagram of Sn-9Zn binary eutectic alloys. Energy-dispersive X-ray spectroscopy (EDX), is an analytical technique used for the elemental analysis or chemical characterization of a sample. It relies on an interaction of some source of Xray excitation and a sample. EDX pattern for the tested alloy is shown in Fig.(16). Using EDX test, the true chemical structure of the tested samples is lists in Table (1)

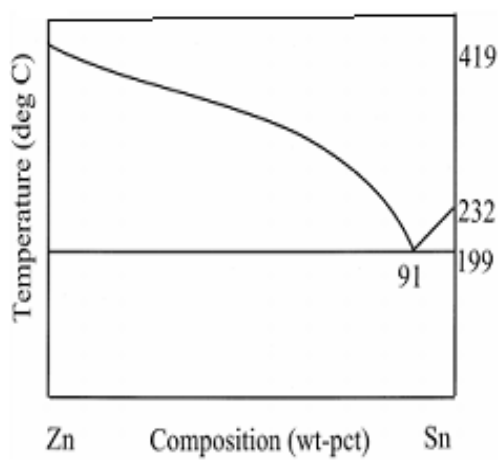

Fig.15: Phase diagram for Sn-9Zn binary system 

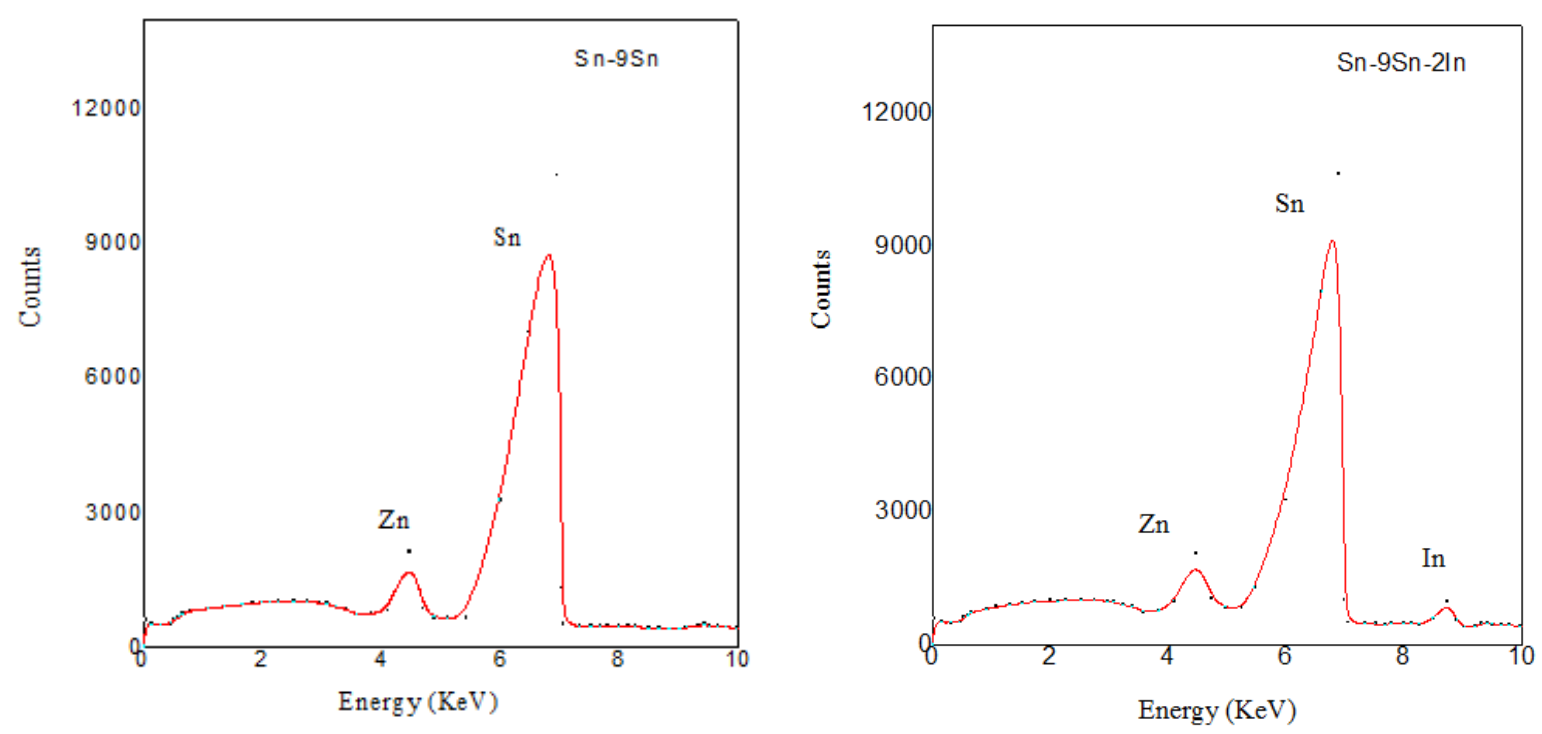

Fig.(16): Energy-dispersive X-ray spectroscopy ( EDX)

\section{Conclusion}

The major conclusions to be drawn from this work may be outlined as follows:

1. The transient creep parameters $n$ and $\beta$ have a high temperature reliance represent by an activation energy in supported dislocation intersection and grain boundary sliding, the creep parameters $n$ and $\beta$ have more values for ternary alloys than binary alloys, while activation energy of ternary alloys is less than the binary alloys.

2 . The as-cast microstructures of Sn-9Zn test solder is characterized by separate course eutectic regions $(\mathrm{Sn}$ and $\mathrm{Zn}$ ) and primary $\beta$-Sn dendrites. Addition of 2In to the Sn-9Zn solders results in significant increase in ductility and was found to be enhancing the plasticity of the ternary alloys; this behaviour was attributed to refine the coarse needle-like Zn-rich phase and formation of intermetallic compounds (IMCs) and, $\gamma$-In $\mathrm{Sn}_{4}$ and $\beta-\operatorname{In}_{3} S n$; which improve the microstructure of the alloy. Consequently, the mechanical properties of Sn-9Zn-2In solder may be enhanced.

3 . With the addition of $2 \mathrm{Ti}$ into Sn-9Zn solder, considerable perfection in creep is refinement. i.e. ternary alloy is more in elongation than binary.

\section{References}

1-Lin, C.P., Chen, C.M., Yen, Y.W., Wu, H.J. and Chen, S.W. Interfacial reactions between high-Pb solders and Ag, J. Alloys Compd., 509, 35093514(2011).

2-Keller, J., Baither D., Wilke U., Schmitz G., Yu Q., Xie, H.P. and Wang, L. Development of high strength Sn-0.7Cu solders with the addition of small amount of Ag and In, Acta Mater. 59, 2731-2741(2011).

3- El-Daly, A.A., Fawzy, A., Mohamad, A.Z., and ElTaher, A.M. Microstructural evolution and tensile properties of Sn-5Sb solder alloy containing small amount of Ag and $\mathrm{Cu}, \quad J$. Alloys Compd. 509 45744582(2011).

4-Gain, A.K., Fouzder, T., Chan ,Y.C., Sharif, Wong, A., N.B., and Yung,W.K.C. The influence of addition of $\mathrm{Al}$ nano-particles on the microstructure and shear strength of eutectic $\mathrm{Sn}-\mathrm{Ag}-\mathrm{Cu}$ solder on $\mathrm{Au} / \mathrm{Ni}$ metallized Cu pads, J. Alloys Compd. 506 216223(2010).

5-]Lin, C.Y., Mohanty, U.S., and Chou J.H. High temperature synthesis of Sn-3.5Ag-0.5Zn alloy nanoparticles by chemical reduction method, J. Alloys Compd. 501 204-210(2010).

6-]Gain, A.K., Fouzder, T., Chan, Y.C., and Yung , W.K.C. Microstructure, kinetic analysis and hardness of Sn-Ag-Cu-1wt\% nano- $\mathrm{ZrO}_{2}$ composite solder on OSP-Cu pads, J. Alloys Compd. 509 3319-3325(2011). 7-El-Daly, A.A., and Hammad, A.E. Development of high strength $\mathrm{Sn}-0.7 \mathrm{Cu}$ solders with the addition of small amount of Ag and In, J. Alloys Compd. 509, 8554-8560(2011).

8-]Zeng K., and Tu , K.N. Solder join Technology, Mater. Sci. Eng. R38 55-105(2002). 
9-Wang ,X., Liu ,Y.C, WeiH .X. Gao P, and Jiang L.M. Yu, Strengthening mechanism of SiC-particulate reinforced Sn-3.7Ag-0.9Zn lead-free solder, Mater. Science and Engineering: A, 480, (2), 662-665(2009). 10-Ochoa, F., and William, J.J. S, and Chawla, N. Effects of cooling rate on the microstructure and tensile behavior of a Sn-3.5wt.\%Ag solder J. Electron. Mater. 32 1414-1420(2003).

11-Huang, M.L. and Wang L. Effects of $\mathrm{Cu}, \mathrm{Bi}$ and In on microstructure \& tensile properties of $\mathrm{Sn}-\mathrm{Ag}-\mathrm{X}(\mathrm{Cu}$, Bi, In solders), Mater. Trans. A 36 1439-1446(2005). 12-Ventura T., Terzi S., Rappaz M., and Dahle A.K. granular modeling and in situ X-ray tomographic imaging: a comparative study of hot tearing formation and semi-solid deformation in $\mathrm{Al}-\mathrm{Cu}$ alloys Acta Mater. 42.03.044(2011) .

13-Tsao LC, Chang SY, Lee CI, Sun WH, and Huang $\mathrm{CH}$. Effects of nano- $\mathrm{Al}_{2} \mathrm{O}_{3}$ additions on microstructure development and hardness of $\mathrm{Sn}_{3.5} \mathrm{Ag}_{0.5} \mathrm{Cu}$ solder Mater Des; 31:4831-5(2010).

14-Hu Y, Xue S, Ye H, Xiao Z, Gao Ll, and Zeng G. Reliability studies of $\mathrm{Sn}-9 \mathrm{Zn} / \mathrm{Cu}$ and. Sn-9Zn-0. $06 \mathrm{Nd} / \mathrm{Cu}$ joints with aging treatment, Mater Des; 34: 768-75(2012).

15-Li G, Shi Y, Hao H, Xia Z, Lei Y, and Guo F. Effect of phosphorus element on the comprehensive properties of $\mathrm{Sn}-\mathrm{Cu}$ lead-free solder, $J$ Alloy Com.; 491: 382-5(2010).

16- Wei X, Huang H, Zhou L, Zhang M, and Liu X. On the advantages of using a hypoeutectic $\mathrm{Sn}-\mathrm{Zn}$ as lead-free solder material Mater Lett; 61: 655-8(2007).

17- Wei XQ, Zhou L, Huang HZ, and Xiao HB. Viscosity transition of ZnO-containing rosin Mater Lett; 59:1889-92(2005).

18-El-Daly AA, and Hammad. Elastic properties and thermal behavior of $\mathrm{Sn}-\mathrm{Zn}$ based lead-free solder alloys, J Alloys Comp;505:793-800(2010).

19-El-Daly AA, Swilem Y, Makled MH, El-Shaarawy MG, and Abdraboh AM. Formation mechanisms of precipitates in an $\mathrm{Al}-\mathrm{Cu}-\mathrm{Li}-\mathrm{Zr}$ alloy and their effects on strength and electrical resistance of the alloy. $J$. Alloys Compd. 484 134-142(2009).

20-Massalski T.B., PHASE DIAGRAMS and types of phases Editor-in-Chief; vol.2, ASM, International, Ohio, p. 3416(1992).

21-El-Daly A.A., Hammad A.E., Al-Ganainy G.A., and Ibrahiem A.A., Elastic properties and thermal behavior of Sn-Zn based lead-free solder alloys Materials and Design 52 966-973(2013).
22-Shalaby Shalaby R. M. Crystal Research Technology, Volume 45, Issue 4, April, 427432(2010).

23-Saker M.S., Mohamed A.Z., El-Daly A.A., AbdelDaiem A.M., and Bassyouni A.H. Transient and steady-state creep characteristics of Transformations in Al-Zn Binary Alloys, Egypt. J. Solids B2, p.34(1990). 24-Salem M.Y. Effects of $\mathrm{Cu}$ addition on creep characteristics of Sn-9Zn lead-free solders; Egypt. J. Solids, Vol. (39); 107-121(2016).

25-Fawzy A., Fayek S.A., Sobhy M., Nassr E., Mousa M.M., and Saad G. Tensile creep characteristics of Sn-3.5Ag-0.5Cu (SAC355) solder reinforced with nano-metric $\mathrm{ZnO}$ particles, Materials Science and Engineering, A603, p.1(2014).

26-Salem M.Y. Transient and steady-state creep characteristics of Transformations in Al-Zn Binary Alloys, International Journal of New Horizons in Physics Vol. 4, No. 2, 21-33(2017).

27-El-Daly A.A., Abdel-Daiem A.M., and Salem M.Y, Transient creep characteristics in two $\mathrm{Pb}-\mathrm{Sn}-\mathrm{Zn}$ ternary alloys Mater. Chem. Phys. 71, p. 111(2001).

28-El-Daly A.A., Abdel-Daiem A.M., and Yousf M. Effect of isothermal ageing on the electrical resistivity and microstructure of $\mathrm{Pb}-\mathrm{Sn}-\mathrm{Zn}$ ternary alloys, Materials Chemistry and Physics 74, 43-51(2002).

29-Fawzy A., Fayek S.A., Sobhy M., Nassr E., Mousa M.M., and Saad, G., Effect of $\mathrm{ZnO}$ nanoparticles addition on thermal, microstructure and tensile properties of Sn-3.5 Ag-0.5 Cu (SAC355) solder alloy, J Mater Sci, Mater Electron, 24, 3217(2013).

30- El-Daly A.A, Mohamad A.Z, Fawzy A., and ElTaher A.M. creep behaviour of near- peritectic Sn5Sb solders containing small amount of $\mathrm{Ag}$ and $\mathrm{Cu}$, Mater. Sci. and Eng.A 528, 1055 -1062(2011).

31-El-Daly A.A., Abdel-Daiem and A.M., Salem M.Y. Transient creep characteristics in two Pb-Sn-Zn ternary alloys, Egypatian Journal of Solids, Vol, 21, No.1, , 120(2000).

32- Takahashi, O., Terada, Y., Takeyama, M., Matsuo ,T. Creep characteristics and internal stress in $\gamma$-TiAl, Mater. Sci. Eng. A 329 835(2002).

33- El-Daly, A.A., Swilem, Y., Hammad, A.E., Creep properties of Sn-Sb based lead-free solder alloys, $J$. Alloys Compd. 471 98-104(2009).

34-Bhatia, M. A., Rajagopalan M., Darling K. A., Tschopp, M. A., Solanki K. N. The role of Ta on twinnability in nanocrystalline Cu-Ta alloys; Journal of Mate. Res. Letters , Vol. 5, ,48-54(2017). 